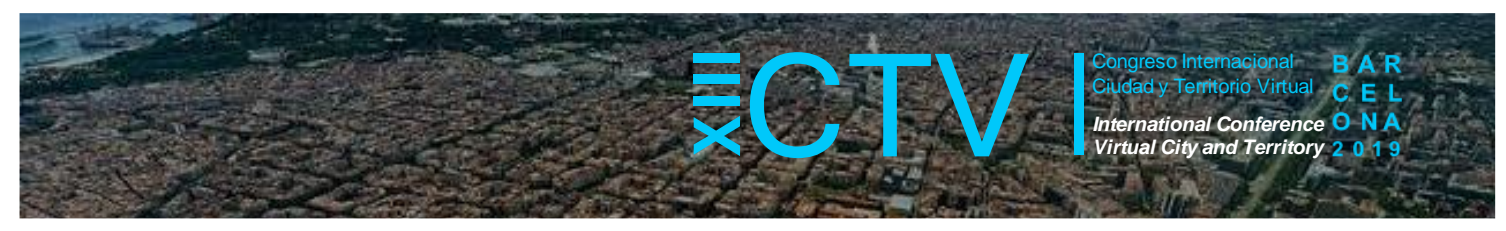

\title{
MECANISMO DE DESARROLLO LIMPIO (MDL) Y BONOS VERDES COMO MOVILIZADORES FINANCIEROS ¿UNA OPORTUNIDAD PARA LAS INVERSIONES ALINEADAS AL CLIMA EN LATINOAMÉRICA?
}

\author{
Lino, Ketty ${ }^{1 *}$; Marmolejo, Carlos
}

Remisión inicial: 2019-06-13; Remisión definitiva: 2019-09-29; Publicación: 2019-12-21

Citación: Lino, K. y Marmolejo, C. (2019). Mecanismo de Desarrollo Limpio (MDL) y bonos verdes como movilizadores financieros ¿Una oportunidad para las inversiones alineadas al clima en Latinoamérica? En XIII CTV 2019 Proceedings: XIII International Conference on Virtual City and Territory: "Challenges and paradigms of the contemporary city": UPC, Barcelona, October 2-4, 2019. Barcelona:CPSV, 2019, p. 8543. E-ISSN2604-6512.DOI http://dx.doi.org/10.5821/ctv.8543

\begin{abstract}
Resumen
El clima está cambiando, la atmósfera y el océano se han calentado, los volúmenes de nieve y hielo han disminuido, el nivel del mar se ha elevado y las concentraciones de gases de efecto invernadero han aumentado (IPCC,2013). Este peligro eminente del cambio climático ha convocado a la comunidad internacional a tomar medidas financieras urgentes para afrontarlo. Incorporar las finanzas verdes en dicho proceso, ha sido asumido por los países firmantes del Protocolo de Kioto en 1997 y posteriormente a través del Acuerdo de París en el 2015, ambos acuerdos, convocados por la Convención Marco de las Naciones Unidas (CMNUD).
\end{abstract}

En el Protocolo de Kioto, los países tanto desarrollados como subdesarrollados, se comprometieron a asumir la financiación para la reducción de las emisiones de los Gases Efecto Invernadero (GEI) a través de una estrategia denominada Mecanismo de Desarrollo Limpio (MDL), que consiste en que un país desarrollado que haya asumido el compromiso de reducir o limitar las emisiones, debe implementar proyectos de reducción de las emisiones en países en desarrollo a cambio de créditos por Reducciones Certificadas de las Emisiones (RCE) ${ }^{2}$ (Ledezma \& Caballero, 2013a) los cuales son instrumentos financieros negociables en el mercado de carbono.

A nivel mundial la expedición de RCE al final del primer periodo compromiso de Kioto (2008-2012), superó los 1000 millones de unidades, lo cual muestra el dinamismo de dicho mecanismo (UNFCCC,2011). Paralelamente los Bonos Verdes (BV) o títulos de deuda de renta fija son otro mecanismo financiero de mercado alineados al clima, emitidos por organismos multilaterales, entes públicos estatales o municipales, y entidades financieras y no financieras de carácter privado. La emisión de Bonos Verdes en Latinoamérica ha mostrado un desarrollo conservador de acuerdo al informe del Climate Bonds Initiative (2018)

El presente estudio tiene como objetivo obtener un análisis comparativo de los dos mecanismos descritos anteriormente, en cuanto su aporte a la política energética de la región. La metodología parte del estudio de casos en países que han implantado de forma importante dichos instrumentos (Brasil y México).

Para el análisis comparativo, se revisaron aspectos relacionados con los procedimientos, la evolución, las ventajas y/o desventajas de implementación, poniendo especial énfasis en los países seleccionados y desde el punto de vista del atractivo para los inversores internacionales. La elaboración del estudio requirió una revisión bibliográfica de fuentes académicas (tesis doctorales), documentos normativos relacionados con la inversión en el mercado de capitales, fuentes estadísticas relacionadas con organismos que entregan información de las finanzas latinoamericanas, páginas webs oficiales y una revisión de artículos científicos.

Los recursos obtenidos por Latinoamérica y el Caribe (ALC) para la aplicación de proyectos MDL como resultados de la implementación de proyectos energéticos son importantes. Este mecanismo ha permitido realizar inversiones en tecnologías con menor consumo de energía. Entre las principales barreras para su desarrollo se evidencian la falta de diversificación de emisores y el vaivén del mercado de carbono que desalienta las inversiones. Respecto a los bonos

\footnotetext{
${ }^{1}$ Licenciada en Economía, Doctoranda en Gestión y Valoración Urbana, CPSV-UPC; Dr. Arquitecto, Departamento de Tecnología de la Arquitectura, Investigador del Centro del Política de Suelo y Valoraciones, CPSV-UPC, https://orcid.org/0000-0001-7051-7337. * Correo de contacto: ketty.lino@upc.edu

2 Las "reducciones certificadas de emisiones" o "RCE", acepción española de "certified emissions reductions" (CER)
} 


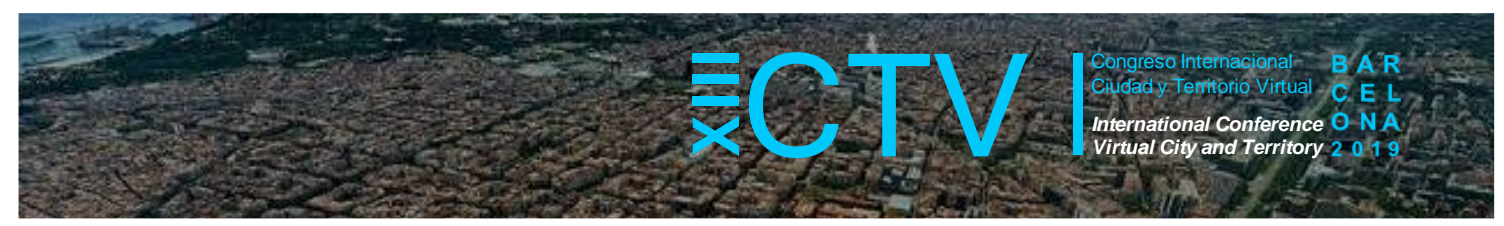

verdes el mercado es voluble y aún requiere condiciones estratégicas para su desarrollo. Brasil está a la vanguardia en la atracción de los dos mecanismos, la banca de desarrollo ha jugado un papel importante en el respaldo de dichos instrumentos.

Los resultados sugieren que, entre los mecanismos analizados, aquéllos altamente participados por el Estado son los que tienen mejores resultados en términos de inversiones energéticas. Respecto al MDL, existen expectativas sobre qué sucederá en el 2020 cuando concluya el compromiso del Protocolo de Kioto y por ende el proceso formal de movilización de recursos hacia los países en vías de desarrollo. Los bonos presentan potencialidades de financiación en el mercado verde, pero no se visualiza un horizonte seguro en los mercados latinoamericanos.

\section{Abstract}

Climate is changing, the atmosphere and the ocean are warming up, snow volumes and ice are diminishing, sea levels are increasing and greenhouse gas emissions keep increasing (IPCC,2013). The upcoming danger of climate change has invoked the international community to take immediate action to tackle it. Embracing green finance tools within this process has been ratified by several countries by the Kyoto Protocol in 1997 and lately through the Pari Agreements in 2015, both agreements convened by the United Nations Framework Convention on Climate Change (UNFCCC).

In the Kyoto Protocol, both developed and developing countries agreed to finance the reduction of greenhouse gas emissions through the Clean Development Mechanism (CDM), in which developed countries with the commitment to reduce or limit emissions, must implement emission reduction projects in developing countries in exchange for credits for Certified Emission Reductions (CERs) (Ledezma \& Caballero, 2013a) which may be traded in carbon emissions trading schemes.

Globally, the issuance of CERs at the end of the first Kyoto commitment period (2008-2012), exceeded 1,000 million units, which shows the dynamism of the mechanism (UNFCCC, 2011). On the other hand, Green Bonds (GB) or fixed income debt securities are another climate-aligned financial market mechanism issued by multilateral organizations, state or municipal public entities, and private financial and non-financial entities. The issuance of Green Bonds in Latin America has shown a conservative development according to the report of the Climate Bonds Initiative (2018).

The aim of this study is to obtain a comparative analysis of the two mechanisms described above, in terms of their contribution to the region's energy policy. The methodology starts from the case study in countries that have implemented such instruments in a relevant manner (Brazil and Mexico).

For the comparative analysis, aspects related to the procedures, the evolution, the advantages and / or disadvantages of implementation were reviewed, with special emphasis on the selected countries and from the point of view of their attractiveness for international investors. The preparation of the study required a bibliographic review of academic sources (doctoral theses), normative documents related to investment in the capital market, statistical sources related to organizations that provide information on Latin American finances, official websites, and a review of scientific articles.

The resources obtained by Latin America and the Caribbean (LAC) for the application of CDM projects as a result of the implementation of energy projects are significant. This mechanism has promoted investments in technologies with lower energy consumption. The main barriers to its development are the lack of diversification of emitters and the fluctuation of the carbon market that discourages investments. Regarding green bonds, the market is fickle and still requires strategic conditions for its development. Brazil is at the forefront in attracting the two mechanisms; development banking has played an important role in supporting these instruments.

Main conclusions: The results suggest that, among the analyzed mechanisms, those highly participated by the State are the ones that have better results in terms of energy investments. Regarding the CDM, there are expectations about what will happen in 2020 when the commitment to the Kyoto Protocol will conclude and therefore the formal process of mobilizing resources towards developing countries. Green Bonds have financing potentials in the green market, but there is no clear horizon in Latin American markets.

Palabras Claves: Financiación; Latinoamérica; MDL; Bono Verde

Key words: Key words: Financing, Latin America, CDM, Green Bonds 


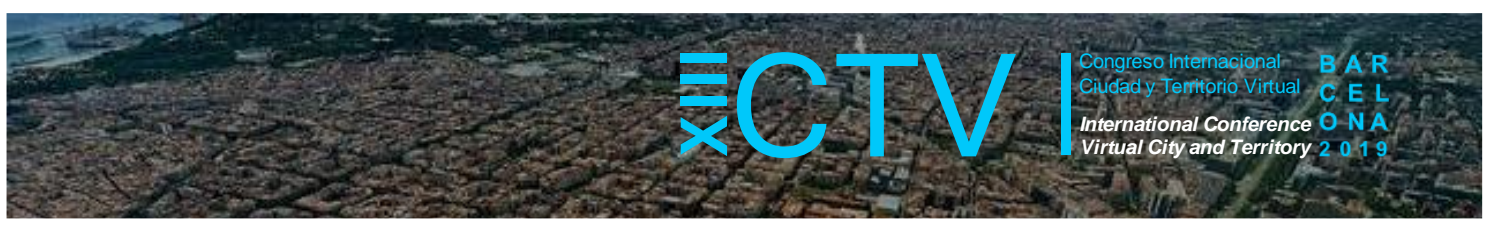

\section{Antecedentes}

\subsection{Latinoamérica y el Caribe en el contexto de la emisión de Gases Efecto Invernadero}

Las emisiones de Gases efecto invernadero $(\mathrm{GEI})^{3}$ al no permanecer dentro de los límites de una región o país contribuyen al cambio de clima global, por lo cual todos los países se ven afectados independientemente de su responsabilidad o no en la generación de éstas. A nivel mundial la tendencia la emisión de dióxido de carbono $(\mathrm{CO} 2)^{4}$ es creciente, en el periodo analizado (Ver fig. 1) crece a pasos agigantados, de tal manera que en el año 2014 bordea los 40 millones de kilotoneladas, regiones como América del Norte superan los 6 millones, Asia meridional y el Pacífico, que incluye China, sobrepasa los 14 millones, La Unión Europea se ubica debajo de los 4 millones con una tendencia decreciente y América Latina y el Caribe (ALC) con alrededor del $9 \%$ de la población mundial no alcanza los 2 millones. Las principales causas provienen del uso de energía basada en combustibles fósiles y el crecimiento económico (IPCC, 2013). En ALC $^{5}$ México y Brasil lideran la contaminación, pues juntos contribuyen con más de la mitad de la emisión de GEI en la región. En el año 2012 los países con mayor emisión originados por la generación de energía eran México con 490,69 mtCO2e, seguido por Brasil con 469,73 mtCO2e, y en tercer lugar Venezuela con 232,86mtCO2e (Benites-Lázaro,2015.)

Figura 1. Emisiones de Kilotoneladas (kt) $\mathrm{CO}_{2}$

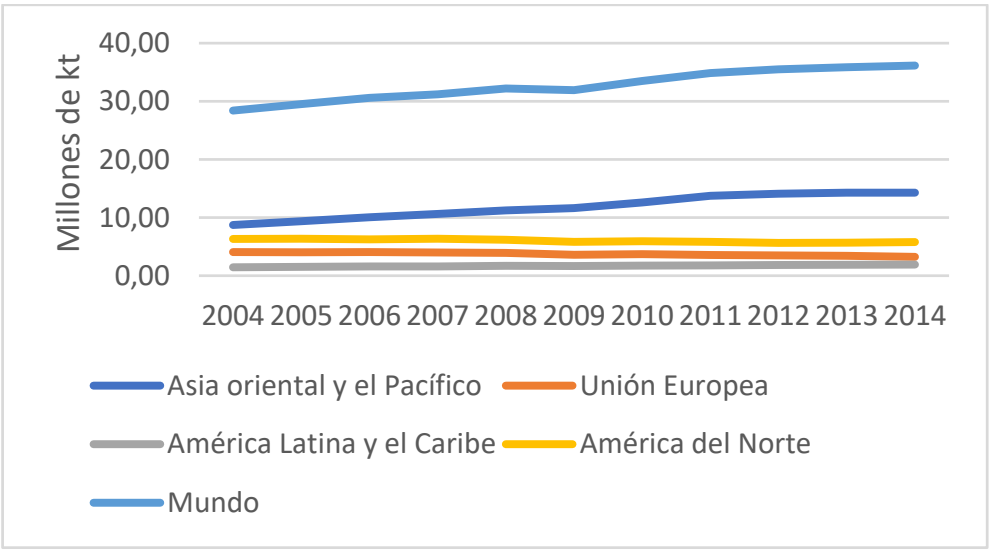

Fuente: Elaboración propia con datos del Banco Mundial.

ALC no es representativa en términos de emisiones de GEl en el contexto internacional. Sin embargo, su población está localizada en un sector del globo terrestre con altos peligros derivados del cambio climático. La estructura de esta región incorpora países y ecosistemas muy vulnerables a amenazas de sequía, inundaciones debido a la precipitación extrema, descenso en la producción de alimentos y un aumento de enfermedades transmitidas por vectores (IPCC-2013) cuyos patrones de proliferación están expandiéndose debido al calentamiento global. Respecto a los peligros de la elevación del nivel del mar, más de 7,5 millones de habitantes, $42.600 \mathrm{~km}^{2}$ y un capital construido valorado en 334 mil millones de

\footnotetext{
${ }^{3}$ Más información en el documento de NN UU (1998) Anexo A del Protocolo de Kioto, donde se describe los principales GEI; Dióxido de Carbono (CO2), Metano (CH4), Óxido Nitroso N2O y otros gases industriales fluorados.

${ }^{4}$ Más información: https://datos.bancomundial.org/indicator/EN.ATM.CO2E.KT

${ }^{5}$ Más información disponible en: https://expansion.mx/mundo/2017/06/09/mexico-y-brasil-lideran-la-emision-de-dioxidode-carbono-en-america-latina
} 


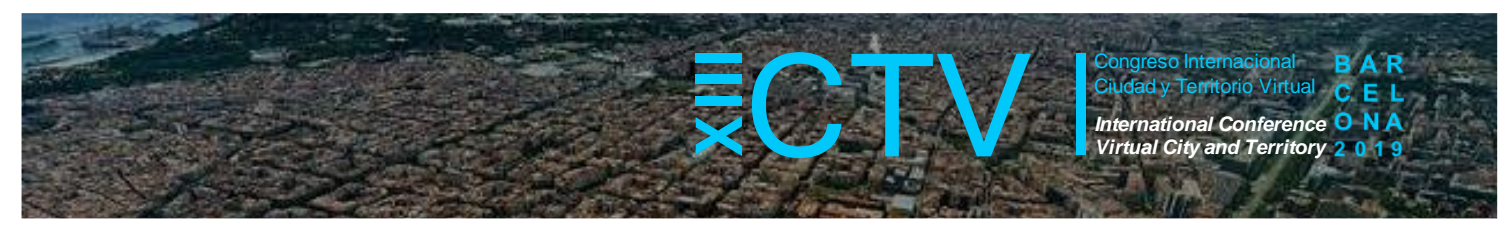

dólares estadounidenses se encuentran actualmente en riesgo; si se produce dicho aumento, millones de habitantes estarán expuestos a peligro a finales de siglo (Reguero et al, 2015). Los problemas del cambio de clima en la población ya se visualizan en diversos estudios como el de Silveira et al (2019); el cual demuestra que el incremento de las altas temperaturas trae aparejado el riesgo de mortalidad especialmente para las ciudades más calurosas en la región. Cabe destacar que los efectos del cambio climático podrían socavar el progreso alcanzado en los últimos decenios por los países de América Latina en su lucha contra la pobreza.

\subsection{La apuesta por el desarrollo con energía renovable (ER)}

Aunque ALC no genera gran cantidad de emisión de GEI con relación a las demás regiones. Se ha preocupado por lograr un desarrollo económico con inversiones energéticas en un contexto de urgencia de mitigación de emisiones de gases. Este incremento de inversiones se evidencia muy a pesar de que las economías de la mayoría de los países de $\mathrm{ALC}^{6}$ dependen básicamente de las exportaciones de combustibles fósiles. Venezuela, Brasil y México disponen de más del $90 \%$ de las reservas de petróleo de la región (Sheinbaum-Pardo et al 2012b). La apuesta por las energías renovables se pone de relieve en el estudio "Prospectiva de Energías Renovables 2012-2026 " elaborado por el SENER México (2012). En dicho estudio se destaca Brasil, no solo en el contexto latinoamericano, sino en el mundo entre los países más intensivos en el uso de las energías renovables para la generación de electricidad, compitiendo con Islandia y Noruega.

Las inversiones en cifras de acuerdo a la Agencia Internacional de energía Renovable (IRENA por sus siglas en inglés), se registran desde el 2005 (Ver figura 2), entre 2010 y 2015 la cifra asciende a más de 80.000 millones de USD (excluyendo las grandes hidroeléctricas). En 2015, la inversión alcanzó los 16.400 millones de USD, equivalente al $6 \%$ del total mundial. Según esta fuente entre 2005 y 2009, Brasil concentró más del 70 \% de la inversión en renovables, pero desde 2010 se ha ido diversificando en el resto de la región. De tal manera que el autor revisando cifras de Bloomberg New Energy Finance (2016), afirma que para el año 2015, la inversión de Brasil descendió al $40 \%$ del total regional, equivalente a 7.100 millones de USD.

Dicha fuente afirma que México ha sido el segundo país con altas inversiones en tecnologías renovables, la inversión se duplicó entre 2014 y 2015 hasta alcanzar los 4.000 millones de USD. Chile ocupó el tercer lugar con una inversión de 3.400 millones de USD: un crecimiento del $150 \%$ con respecto a 2014. En Centroamérica Honduras es el principal receptor de inversiones en renovables en proporción al PIB. Además, IRENA estima la inversión regional total en grandes hidroeléctricas en 9.000 millones de USD en 2015.

Respecto a tipo de tecnologías la tendencia de los últimos años refleja un descenso de la inversión en biocombustibles líquidos, compensado por un notable crecimiento de la inversión en energía eólica y, más recientemente, solar. En los tres últimos años, la inversión en energía eólica ha aumentado rápidamente hasta alcanzar dos tercios de la inversión en renovables. Desde 2012, la energía solar fotovoltaica ha emergido como importante foco de inversión, sobre todo en Chile, Brasil y México (IRENA,2016). Lo anteriormente descrito muestra la rápida evolución del sector energético hacia una gama más diversificada de fuentes de ER.

\footnotetext{
${ }^{6}$ Ampliar información https://www.efe.com/efe/america/economia/brasil-registro-en-2018-el-segundo-mayor-superavitcomercial-de-su-historia/20000011-3856536
} 
Figura 2. Inversión en energías renovables 2010-2015: según país (arriba) y tecnología (abajo)

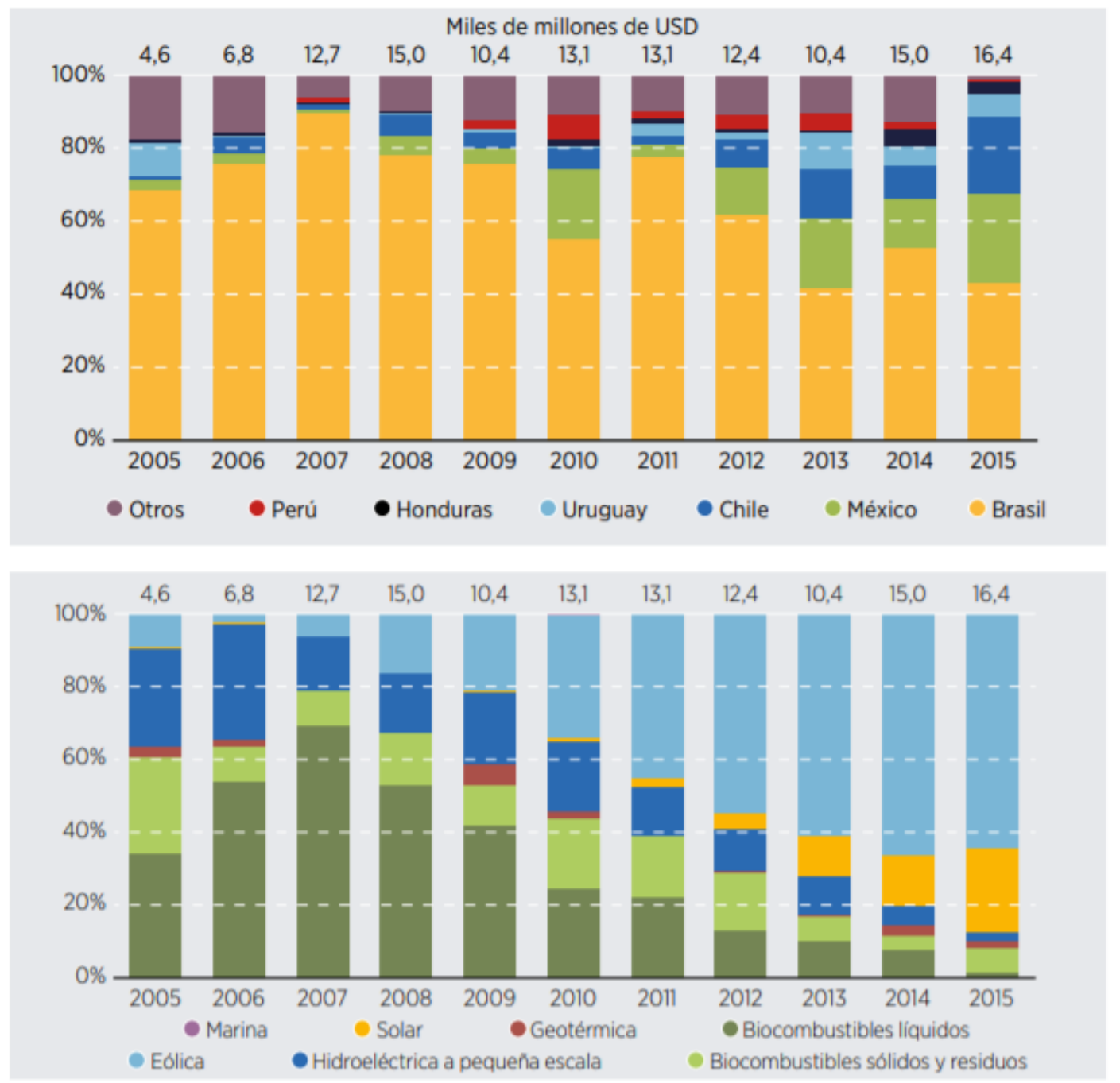

Fuente: Bloomberg New Energy Finance, 2016.

Elaboración IRENA (2016), "Análisis del mercado de energías renovables: América Latina". IRENA, Abu Dabi.

Estudios como Panorama Energético de ALC (2018) que realiza OLADE (2018), corroboran dicha información. Brasil muestra que en el 2017 el 80\% de dicha generación eléctrica provenía de las fuentes renovables (hidráulica, eólica y la solar por este orden). Según dicho estudio, México por su parte dispone de las térmicas no renovales, centrales de combustión interna y de ciclo combinado en la provisión de energía eléctrica; solo el $18 \%$ de la energía es con fuentes renovables. Dicho país muestra avances importantes en: la universalización de la energía, instalación de módulos solares fotovoltaicos en localidades lejanas y dispersas e impulsa políticas de transición energética para promover el uso de tecnologías y combustibles más limpios. Sin embargo, aún tiene un largo camino hacia las energías renovables.

Existen urgencias y retardar la aplicación de medidas supone pérdidas humanas e incremento en los costes económicos de adaptación. Dicha urgencia y la identificación de las herramientas financieras claves, ha convocado a ALC y a toda la comunidad internacional a tomar medidas importantes. 


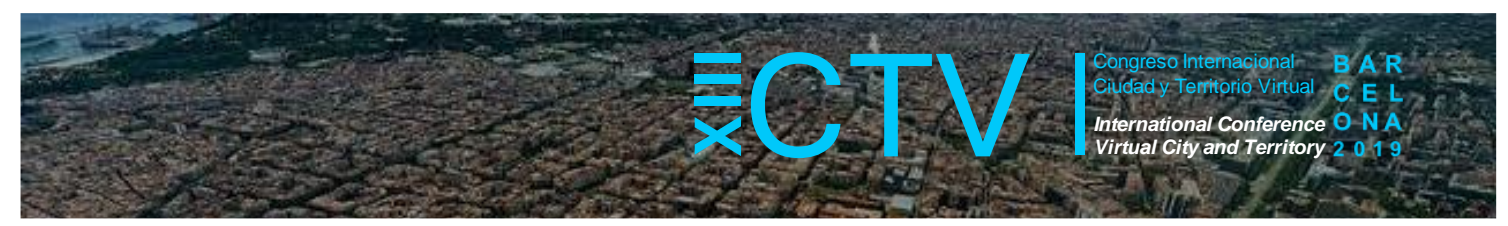

\subsection{Avances en materia de financiación verde en la agenda internacional}

Los espacios internacionales de negociación han sido importantes para debatir sobre las inversiones alineadas al clima y buscar medidas financieras estratégicas para las grandes necesidades de mitigación. Brasil ha estado en la vanguardia, es destacable su participación en las negociaciones de Kioto, que dilucidó el Protocolo de Kioto (PK) a través de una propuesta, que resultó ser la génesis del Mecanismo de Desarrollo Limpio (MDL). La propuesta consistía en imponer límites a las emisiones de los países desarrollados ( anexo I de la CMNUCC) ${ }^{7}$ en base a la responsabilidad histórica que éstos tenían sobre la contaminación atmosférica, con penalizaciones en caso de incumplimiento (Villavicencio, 2013). Sin embargo, el resultado final luego de un largo proceso de negociación entre los países, fue un MDL flexible con rasgos de mercado.

El Acuerdo de París (AP) por su parte, firmado por 174 países, entró en vigor en $2016^{8}$, tiene como estrategia impulsar el rol crítico de la financiación pública de los países desarrollados para acciones destinadas a la mejora de la resiliencia y la adaptación hacia los países en desarrollo. Sugiere movilizar recursos del sector privado, o líneas de inversión del sistema financiero bancario hacia activos basados en tecnologías limpias. Además de trasladar para implementar el Acuerdo mecanismos financieros de la Convención tales como el Fondo Verde para el Clima y el Fondo Mundial para el Medio Ambiente (PNUMA-U. EUROPEA, 2015).

En dicho contexto, el presente estudio hace énfasis en el análisis del MDL y los Bonos Verdes ${ }^{9}$, como movilizadores de financiamiento para cumplir los compromisos, cuyos recursos son dirigidos a financiar proyectos relacionados con el clima, con incidencia y pertinencia directa para los países de ALC.

\section{Mecanismo de desarrollo limpio y bonos verdes, como movilizadores financieros para inversiones}

Los dos instrumentos financieros de mercado han canalizado recursos hacia ALC. El Mecanismo de Desarrollo Limpio (MDL) ha sido implementado de manera oficial ${ }^{10}$ en el contexto del Protocolo de Kioto(PK) y se asegura que los Bonos Verdes (BV), pueden ser instrumentos para financiar proyectos de adaptación y mitigación, como parte del acuerdo climático de París (Banga, 2019).

En el PK los países, tanto desarrollados como en vías de desarrollo, se comprometieron a asumir la financiación para la reducción de las emisiones de los Gases Efecto Invernadero (GEI) a través de una estrategia conjunta denominada Mecanismo de Desarrollo Limpio (MDL). EI MDL consiste en que un país desarrollado que haya asumido el compromiso de reducir o limitar las emisiones, debe poner en práctica o financiar proyectos de reducción de las emisiones en países en desarrollo (Figura 3). A través de tales proyectos, estos países pueden conseguir créditos por

\footnotetext{
${ }^{7}$ Ver: http://unfccc.int/resource/docs/convkp/convsp.pdf Ampliar información; https://unfccc.int/es/news/175-estados-firman-el-acuerdo-de-paris: https://treaties.un.org/Pages/ViewDetails.aspx?src=IND\&mtdsg no=XXVII-7-d\&chapter=27\&clang= en

${ }^{9}$ Según el Banco Mundial Los mercados de capitales pueden cumplir una función clave para respaldar los compromisos del acuerdo sobre el cambio climático de París. Ampliar información en https://www.bancomundial.org/es/results/2017/12/01/green-bonds

${ }^{10}$ Este mecanismo ya se venía implementando, según Jiménez (2007), desde el año 2007
} 


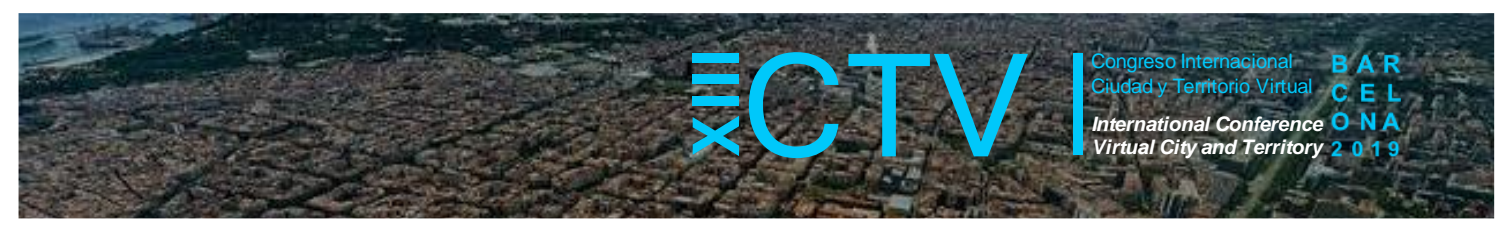

Reducción Certificada de Emisiones (RCE) para cumplir sus propios límites de emisión; reservarlos, o venderlos a otros países industrializados en el marco del sistema de comercio de derechos de emisión del Protocolo (Ledezma \& Caballero, 2013a). Cabe destacar que cada RCE equivale a una tonelada de $\mathrm{CO}_{2}$ eq $^{11}$ reducida, y su precio depende del mercado. La vigencia oficial de este mecanismo ${ }^{12}$ es el mismo que rige al Protocolo de Kioto (2008-2012) y, (20132020). No existen datos de su extensión al futuro.

El Bono Verde se define como un instrumento financiero líquido, o emisión de deuda, cuyo propósito es recaudar recursos financieros tanto en el mercado doméstico e internacional, emitido por organismos multilaterales, entes públicos estatales/municipales o entidades financieras y no financieras. Dichos emisores se comprometen a pagar al inversor una tasa de interés fija (cupón) y a devolver la inversión inicial (capital) en la fecha de vencimiento del instrumento financiero (World Bank 2015). Además, establecen informes del uso de los recursos (inf).

Estos instrumentos financieros se negocian en el mercado de bonos. Según las estadísticas de $\mathrm{CBI}$, existen innumerables bonos que financian proyectos alineados al clima en mayor o menor grado, este análisis se centrará en los denominados bonos verdes etiquetados cuyos recursos son asignados de manera exclusiva a activos verdes. El primer bono verde fue emitido por el Banco Europeo de Inversiones en el 2007.

Figura 3. Mecanismo financieros: en que consisten y como se implementan
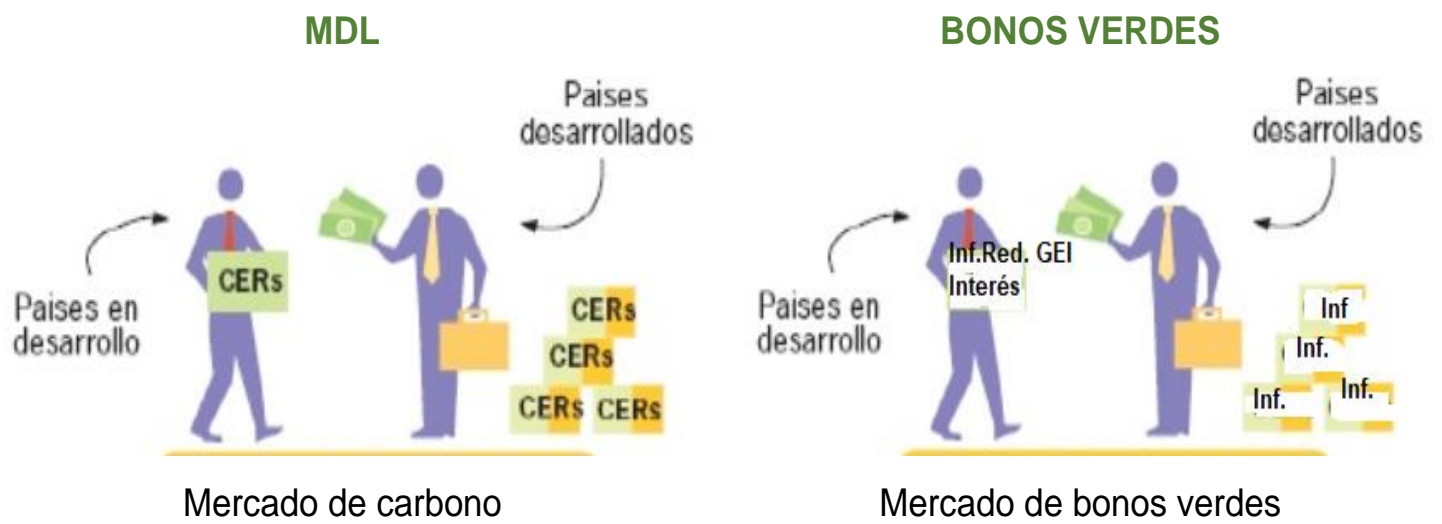

Fuente: Adaptada de imagen original de Jaime Parada (2010) cambio climático: Conceptos y tendencia del mercado de carbono. Recuperado https://es.slideshare.net/fnuno/mercado-del-carbono-p1

Los bonos verdes no tienen características específicas en términos de su estructura financiera (generan interés).

Su principal diferencia con los bonos convencionales es el uso que le darán al financiamiento obtenido, el cual se detalla en el prospecto de colocación (Inf) (México 2, 2018)

\footnotetext{
${ }^{11}$ Cuando hablamos de gases de efecto invernadero (GEI) nos referimos a $\mathrm{CO} 2$ equivalente (CO2 eq), que incluye los seis gases de efecto invernadero recogidos en el Protocolo de Kioto: dióxido de carbono (CO2), metano (CH4), óxido de nitrógeno (N2O), hidrofluorocarburos (HFC), perfluorocarburos (PFC) y hexafluoruro de azufre (SF6) (Oficina Catalana de Cambio Climático, 2011)

${ }_{12}$ Cabe aclarar que la vigencia de los MDL se materializa de manera oficial con la firma del Protocolo de Kioto, sin embargo, informe de UNFCC (2011) registra actividades desde el año 2005.
} 


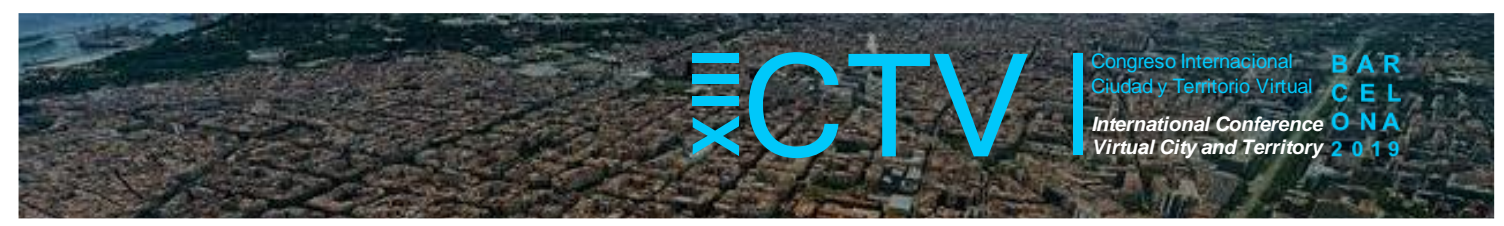

\subsection{Procedimientos e implementación}

\subsubsection{Mecanismo de Desarrollo Limpio (MDL)}

El procedimiento de implementación y la metodología de este mecanismo ${ }^{13}$ han sido diseñados de manera gradual desde las reuniones de las Partes del Protocolo de Kioto (COP/MOP) ${ }^{14}$. Para que un proyecto logre su incorporación en el sistema del MDL, debe existir como requisito una reducción de emisión adicional a la que se produciría en ausencia del proyecto (Una actividad de proyecto MDL es adicional si las emisiones antropogénicas de GEI son reducidas por debajo de lo que hubiese ocurrido en ausencia de que la actividad de proyecto hubiese sido inscrita en el MDL, La demostración de adicionalidad del proyecto, requiere de la definición de una línea base por parte del ejecutor del proyecto) (Villavicencio, 2013). Además, debe acogerse a diversas fases, desde el diseño del proyecto hasta la expedición de las Reducciones Certificadas de las emisiones (RCE). El resultado de este proceso es la generación de la reducción de emisiones de GEl que será adjudicada o comercializada en el mercado de carbono.

El precio del RCE depende de las condiciones de mercado, del tipo de proyecto desarrollado y del momento del ciclo del proyecto en el que se comercializan. Según Villavicencio (2013), el precio se cotiza generalmente con modalidades fijas (no cambian ni se verán afectados por las fluctuaciones del mercado), o flotantes, que es un porcentaje del promedio del precio de los EUA (los permisos de emisión transados en el mercado europeo bajo la modalidad de Emission Trading System ETS); el precio flotante le permite al vendedor acceder a ganancias potenciales, pero también a pérdidas en caso de una caída de los precios en el mercado. Los RCE tienen precios menores cuanto más anticipadamente se vendan respecto a la maduración del proyecto (Villavicencio, 2013). Se negocian de manera bilateral, multilateral o unilateral (Villavicencio, 2013). La Autoridad que expide los RCE respecto de una actividad de proyecto MDL es la Junta Ejecutiva.

\subsubsection{Bonos Verdes (BV)}

La emisión de bonos debe cumplir una serie de procedimientos de transparencia e información útiles sobre todo para el inversor, denominados Green Bond Principles (GBP por sus siglas en inglés), siendo establecidos por la Asociación Internacional de Mercado de Capital (IMCA, por su acrónimo inglés) $)^{15}$ y la Iniciativa de Bonos Climáticos ( $\mathrm{CBI}$, por su acrónimo inglés). Estos establecen las bases o principios que debe regir a un bono verde (ALIDE, 2019). Deben tener un respaldo para asegurar la devolución del capital al inversor (balance, impuestos, tarifas, etc.) El mecanismo se negocia en el mercado nacional e internacional, a través de iniciativas individuales de manera bilateral, o colectivas a través de fondos multilaterales de desarrollo. El Banco Mundial ${ }^{16}$ maneja un fondo verde compuesto por recursos de varios inversores incluyendo

\footnotetext{
13 Ampliar información en https://cdm.unfccc.int/methodologies/index.html

${ }^{14} \mathrm{COP} / \mathrm{MOP}$, este órgano actúa en calidad de reunión de las Partes en el Protocolo de Kioto y está integrado por todas las Partes que han ratificado dicho Protocolo. Se diferencia de La COP como órgano supremo de la Convención Marco de las Naciones Unidas sobre el Cambio Climático, porque se refiere a las Partes signatarias específico del Protocolo de Kioto. La COP-MOP se reunió por primera vez en Montreal en 2005, coincidiendo con la entrada en vigor del Protocolo de Kioto (MITECO,2019.)

${ }^{15}$ ICMA es una asociación compuesta por 460 miembros localizados en 53 países, entre los que se encuentran inversores y entidades bancarias, cuya sede se encuentra en Suiza y cuenta con oficina en París y Hong Kong.

${ }^{16}$ El Grupo Banco Mundial, a través del Banco Mundial y la Corporación Financiera Internacional (IFC) han sido importantes emisores de bonos verdes, al haber recaudado fondos de una amplia variedad de inversionistas institucionales y minoristas. Ampliar información https:/www.bancomundial.org/es/results/2017/12/01/green-bonds
} 


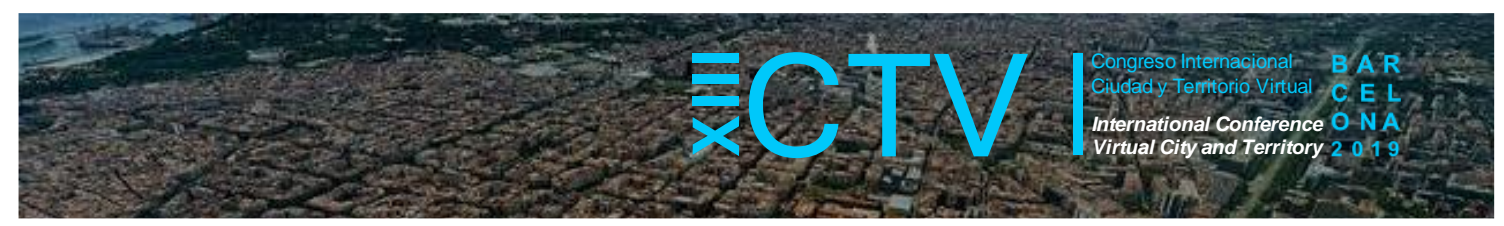

agentes del sector privado de diferentes países. Este organismo a su vez selecciona los proyectos donde canaliza dichos recursos. La existencia de índices ${ }^{17}$ de bonos verdes ha contribuido ampliamente a aumentar la confianza, dando a los inversionistas un medio para evaluar el desempeño y calcular riesgos. Según el informe Climate Bond Initiative (2016), más de la mitad de los bonos se encuentran entre 100 y 500 millones de dólares, el tamaño mínimo de un bono para ingresar a un índice varía, pero comúnmente el valor mínimo se encuentra en alrededor de 200 millones de dólares. El plazo promedio de los bonos verdes etiquetados se encuentra entre 5 y 10 años, contrastando con los demás bonos relacionados con el clima donde el $70 \%$ tiene plazo de 10 años o más (ALIDE,2019).

El procedimiento de emisión del bono verde en un determinado territorio, de acuerdo con la guía por Mexico2 (2018), (Ver fig. 4) se inicia con la identificación de proyectos ${ }^{18}$. Posteriormente lo revisa un tercero independiente(calificado), el cual vigila que los proyectos elegibles cumplan los estándares GBP y CBI. Posteriormente, se inscribe en la Bolsa de Valores, como cualquier otro instrumento de deuda establecido por la Superintendencia del Mercado de Valores (SMV). Luego se subasta el valor en el mercado nacional e internacional y finalmente los recursos de la emisión se canalizan en el proyecto. Cabe indicar que un factor importante para el inversor es que el emisor tenga una buena calificación entregada por una entidad calificadora reconocida en el medio (Credit Rating Agency, DNV GL busines Assurance entre otras).

\section{Figura 4. Proceso de colocación y emisión de bonos verdes}

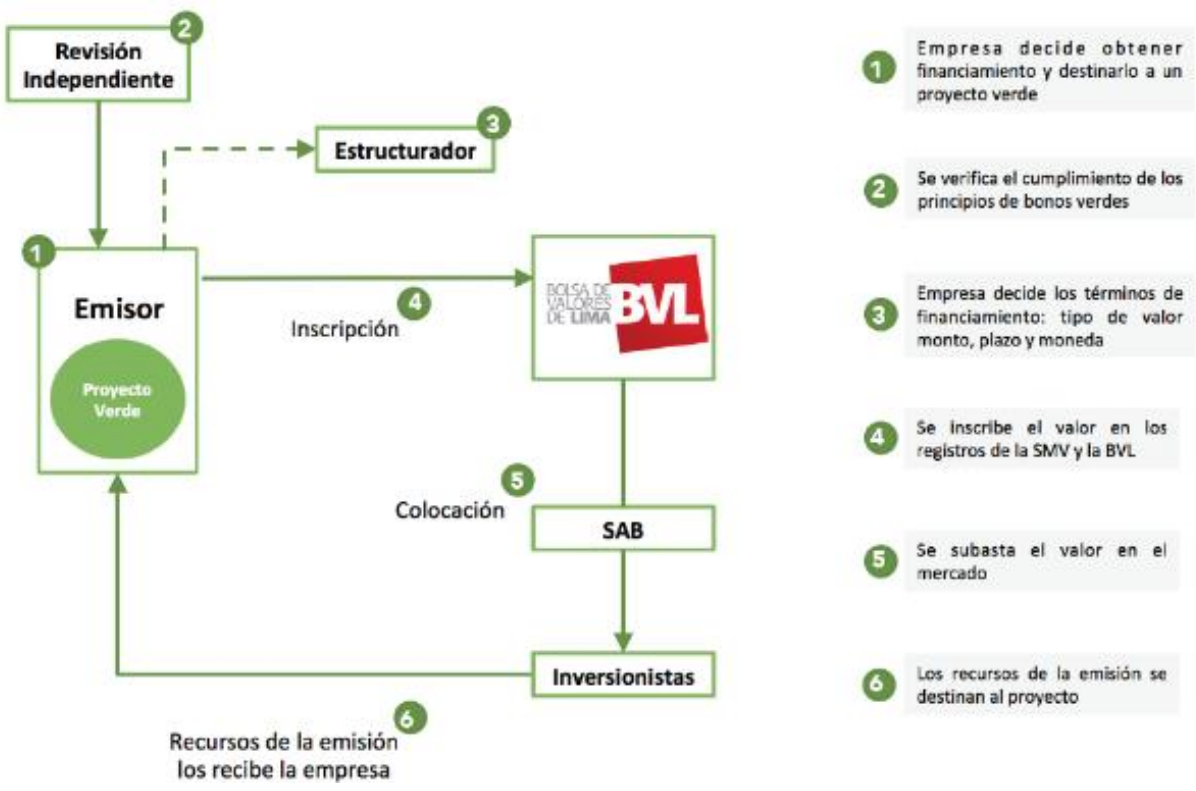

Fuente: Mexico2 (2018)-Guía de Bonos Verdes para el Perú

\footnotetext{
${ }^{17}$ El índice en una sola unidad refleja el precio de los diversos títulos que lo conforman Para integrar el índice, los activos deben cumplir ciertos criterios de selección Los criterios de selección generalmente relacionados a calidad crediticia, montos negociados, vencimiento- liquidez, divisas entre otros, son elaborados por diferentes bancos de inversión y agencias de calificación crediticia. Estándar\&Poor (S\&P), Moody, entre otras. Según ALIDE (2019) Los índices de bonos verdes etiquetados incluyen: S\&P Dow Jones, Solactive, Barclays MSCl y Bank of America Merrill Lynch

${ }^{18}$ Estos deben ser claramente definidos por el emisor y sus impactos deben ser descritos y estimados en la medida de lo posible. Cuando no esté claramente identificado el proyecto, el emisor debe establecer una política que describa los criterios que deberán seguir las inversiones que se realizaran con los fondos (es el caso del Fondo Verde).
} 


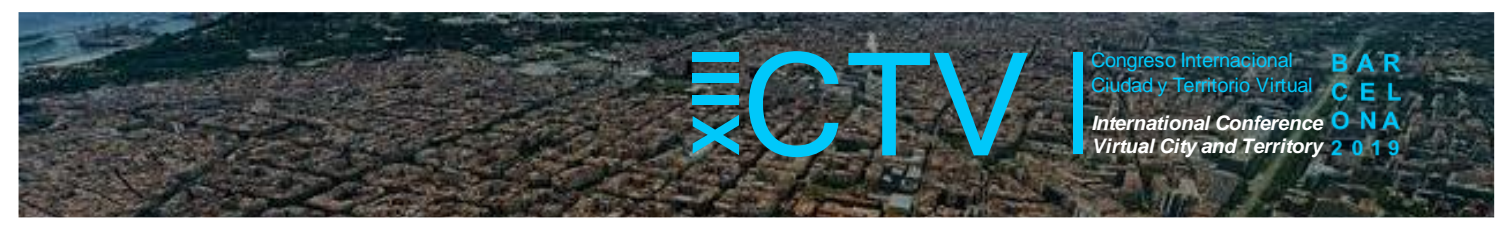

\section{Contribución de los dos mecanismos en la política energética de ALC}

\subsection{El aporte del MDL a las inversiones energéticas}

El potencial de los proyectos MDL puede observarse en el creciente dinamismo de sus transacciones que prácticamente se multiplicaron en los primeros años de vigencia. En el 2007, existía una alta intensidad de la demanda de RCE que venía excediendo la oferta (Jiménez, 2007). La demanda se originaba sobre todo de entidades intermediarias (bróker), las cuales negociaban en el mercado spot del EUETS19, el crecimiento de la actividad se debió a la entrada de vigor del protocolo de Kioto y a la entrada en operación del esquema de comercio de emisiones de la Unión Europea (Eguren C et al.,2007). ALC, en el 2009 alcanzaban el 17\% del total mundial en la implementación de proyectos que generaban una gran cantidad de RCE (UNFCC,2011)

Luego de tener un papel destacado en la recepción de la inversión, ALC ha ido disminuyendo su participación en los proyectos MDL, a fines de 2012, Asia Pacífico (China ya había tomado la delantera, seguido de India, a había tomado la delantera) (Benites- Lázaro, 2015). En el 2019 ALC se mantiene con el $12,9 \%$ de los proyectos MDL, respecto a la cifra total de implementación, manteniéndose activos en Asia con el 83,7\% (UNFCCC,2019). Las cifras de la región a agosto 2019 muestran que de 1110 proyectos que se implementa, el 35\% los desarrolla Brasil, el 18\% México y el 10\% Chile. Los demás están distribuidos entre los demás territorios latinoamericanos(UNEP DTU, 2019)

Para mostrar el comportamiento de los proyectos MDL, tomando en consideración el número de registro de proyectos Benites-Lazaro et al (2018), en un análisis empírico para Brasil, México y Perú muestran el dinamismo en los primeros años. Revisando cifras interanuales (2005-2007) (Ver figura 5) evidencia que Brasil y Perú tuvieron una participación destacada en el desarrollo de proyecto en el año 2012. En el caso de México la mayor participación se evidenció en el 2006. Desde entonces, la tendencia de registro de proyectos MDL anuales ha disminuido.

El estudio muestra que la caída de los precios de los RCEs ha desalentado el mecanismo. Según el autor, el precio promedio (evolución representada en línea negra) de las Reducciones Certificadas de Emisiones (RCE) secundarias alcanzó su nivel más alto de alrededor de $€ 23.10$ / tCO2e durante 2008. Sin embargo, en los últimos años, cayó por debajo de € 0.4 / tCO2e (2017). Respecto a esta desaceleración de precios otros estudios afirman que se debe a los vaivenes del mercado, por la baja demanda de los países con compromiso de reducción de emisiones. Abadía (2014) sugiere que la causa del desplome se debe al desequilibrio entre la oferta y la demanda de créditos de carbono, según dicho autor la principal demanda de RCE ha venido de los gobiernos europeos y de las empresas europeas sometidas al Sistema europeo de Comercio de Derechos de Emisión (EU ETS por sus siglas en inglés) las cuales han puesto limitaciones de uso de créditos a través de los RCE. Así pues, dichas limitaciones y la falta de compromiso de los firmantes del Protocolo de Kioto han hecho que este esquema no pueda cumplir las funciones para la cual fue diseñado (Abadía,2014).

\footnotetext{
${ }^{19}$ El régimen de comercio de derechos de emisión de la UE (RCDE UE es el principal mercado de carbono del mundo y el de mayor tamaño.
} 


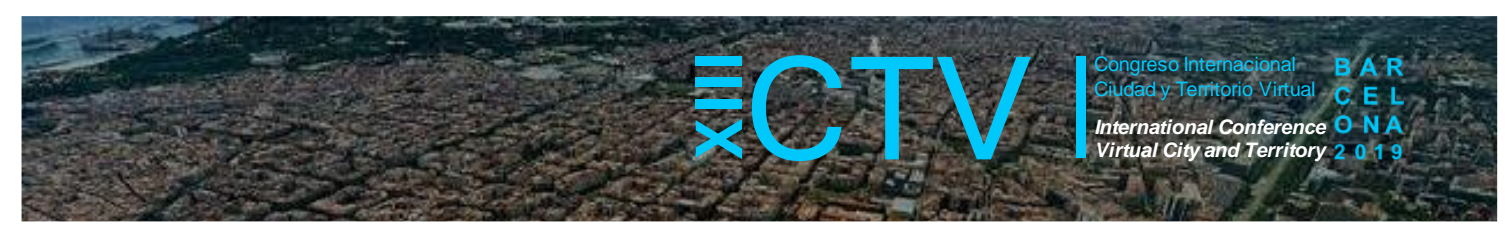

Figura 5. Proyectos de MDL registrados y precio de CER secundario

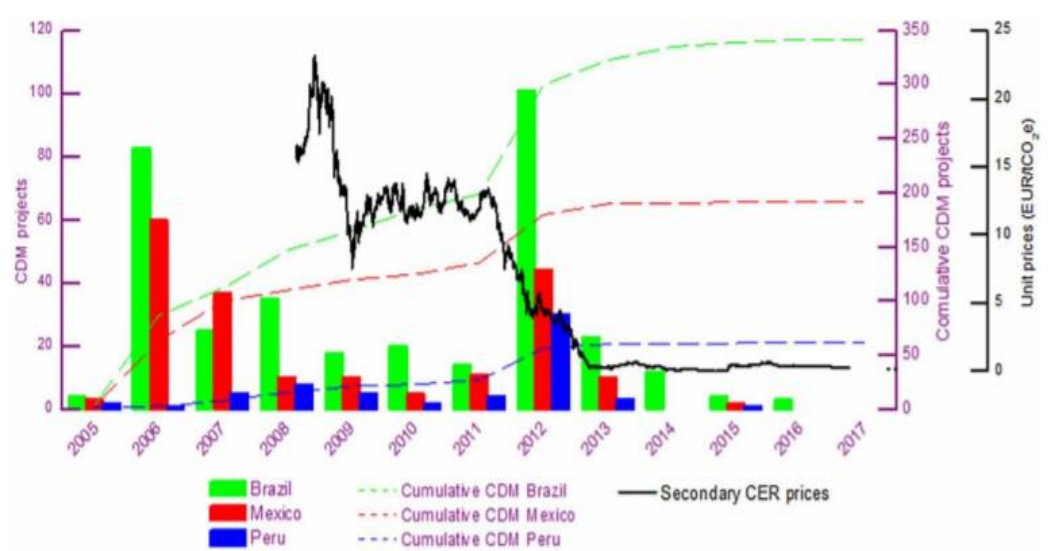

Fuente: CMNUCC (2017b) para CDM y ECX CER. Elaborado: Benites-Lazaro et al, 2018 - Articulo: Business responsibility regarding climate change in Latin America: An empirical analysis from Clean Development Mechanism (CDM) project developers

Respecto a resultados sobre la implementación del MDL en las inversiones alineadas al clima y teniendo como antecedentes el enorme esfuerzo que muestra Brasil desde hace muchos años atrás por las energías limpias (apartado 1.2 del presente documento) ${ }^{20}$. Benites-Lazaro et al (2018) en el estudio antes mencionado, destacan el beneficio que ha recibido la industria energética, principalmente en plantas hidroeléctricas, eólicas y de cogeneración mediante el uso de biomasa (214 proyectos), y seguidamente el manejo de desechos sólidos. Según esta fuente se observan los beneficios también en México, especialmente en la gestión de residuos con 127 proyectos. Sin embargo, la energía renovable ocupa un segundo lugar en dichas inversiones.

Figura 8. Proyectos MDL por sector

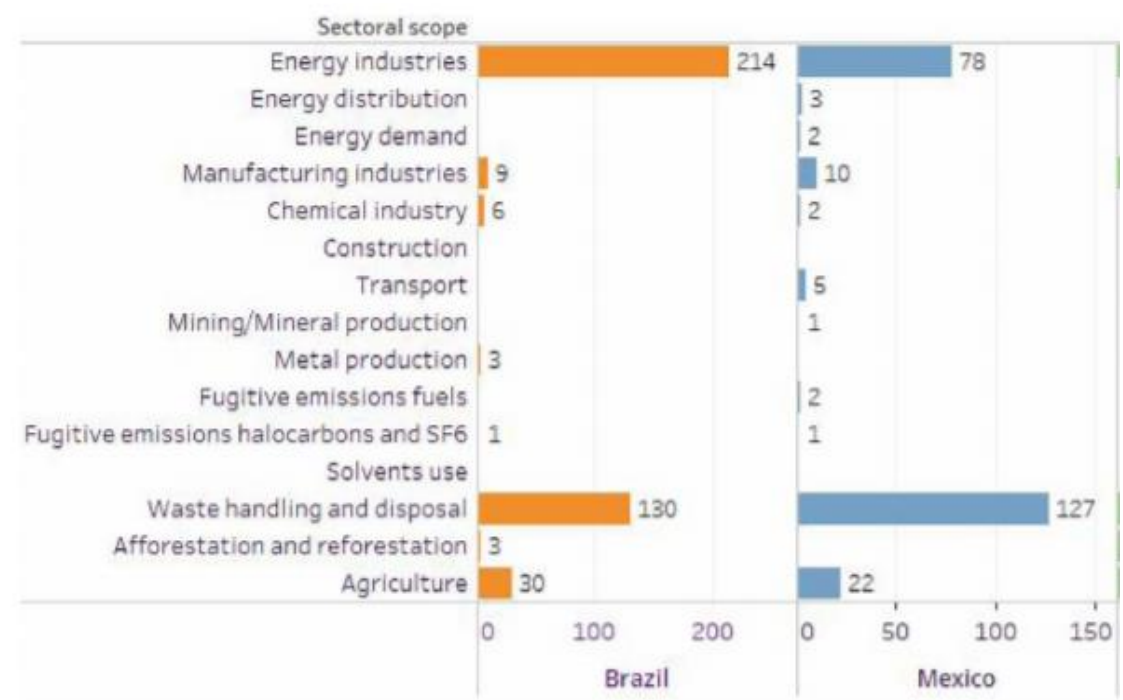

Fuente: CMNUCC (2017b). Elaborado: Benites-Lazaro et al, 2018- Articulo: Business responsibility regarding climate change in Latin America: An empirical analysis from Clean Development Mechanism (CDM) project developers.

\footnotetext{
20 Cabe destacar que es necesario un análisis más profundo de las fuentes específicas que contribuyeron a dicho desarrollo
} 


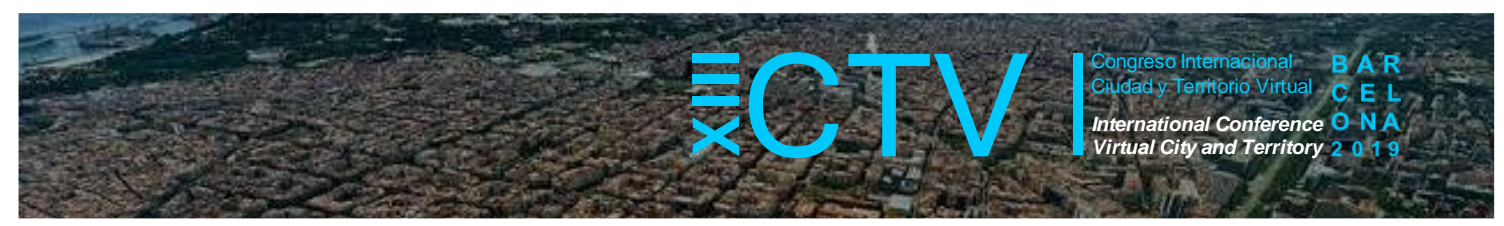

\subsection{La contribución de los bonos verdes (BV) en la política energética}

Los recursos mundiales en circulación por emisión de bonos verdes etiquetados ascienden a alrededor de 118 billones de dólares. Encabezan la emisión Asia, Europa y Norteamérica (China y Francia y Estados Unidos) (Climate Bond Initiative, 2016).

Figura 6. Principales emisores de bonos verdes a nivel mundial (región)

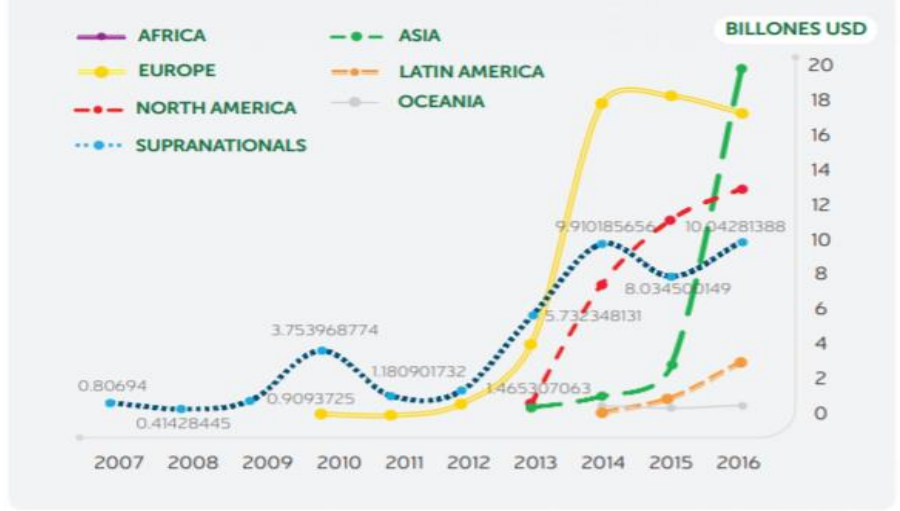

Fuente: Bonos y Cambio Climático-Estado del Mercado,2016

Elaborado: (E3- Gobierno de Colombia- Ecología, Economía y Ética -2018)

En los países de ALC no existe una gran participación de bonos verdes con respecto a las demás regiones (ver fig.6). Según la Comisión Económica para América Latina y el Caribe CEPAL ${ }^{21}$ (2017), históricamente, el sector público ha sido la principal fuente de fondos para proyectos de infraestructura. Otras instituciones financieras, como los bancos comerciales, nacionales, regionales y multilaterales, han proporcionado fuentes suplementarias de capital, pero en cantidades limitadas. Los bonos colocados en los mercados de capitales, locales e internacionales, podrían ser una parte importante de la combinación de fondos de la región para abordar su brecha de infraestructura y desafíos de desarrollo sostenible (CEPAL, 2017). Siendo pequeña la participación en el mercado global de bonos verdes se evidencia un crecimiento positivo en los últimos años, aunque también con caídas drásticas. De acuerdo a informe CBI (2016), en el 2016 se registraron 4,4 billones de dólares en bonos. Brasil y México llevaban el liderazgo de emisión con 2,4 y 1.2 billones respectivamente en el 2017 ya se registraron 8,4 mil millones (CEPAL,2017), y el informe de CBI en el 2018 registró 6,1 millones de dólares

La sensibilidad del mercado de bonos en Latinoamérica se evidencia en un informe del de CBI (2018) sobre la evolución (período 2014-2018) en dicho espacio temporal (Ver fig.7) se observa el liderazgo de Brasil, al final del periodo (2018) tuvo una caída importante lo que desaceleró las emisiones. El análisis sugiere que una de las causas pudo ser el clima de incertidumbre en torno a las elecciones generales brasileñas de dicho año $(C B I, 2018)$. Aunque no se evidencia en la fig. 7, México está presente en la emisión, y le siguen Chile y Colombia. Según la CEPAL (2017) aunque el destino geográfico de la emisión de ALC tanto en el mercado nacional como internacional, en el periodo diciembre de 2014 y agosto de 2017, fue similar; los montos eran muy diferentes, de tal manera que la emisión internacional representaba el $84 \%$ del monto total emitido.

\footnotetext{
${ }^{21}$ Comisión Económica para América Latina y el Caribe (CEPAL), acepción española de Economic Commission for Latin America and the Caribbean (ECLAC)
} 


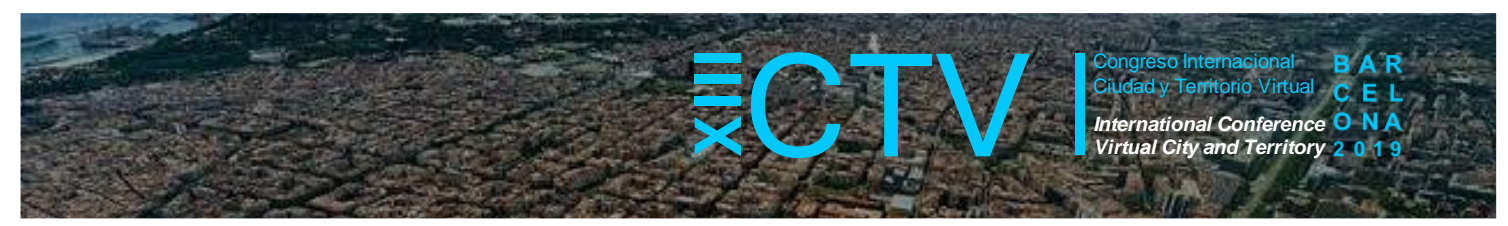

Figura 7. La emisión de bonos verdes se desaceleró en LAC en 2018

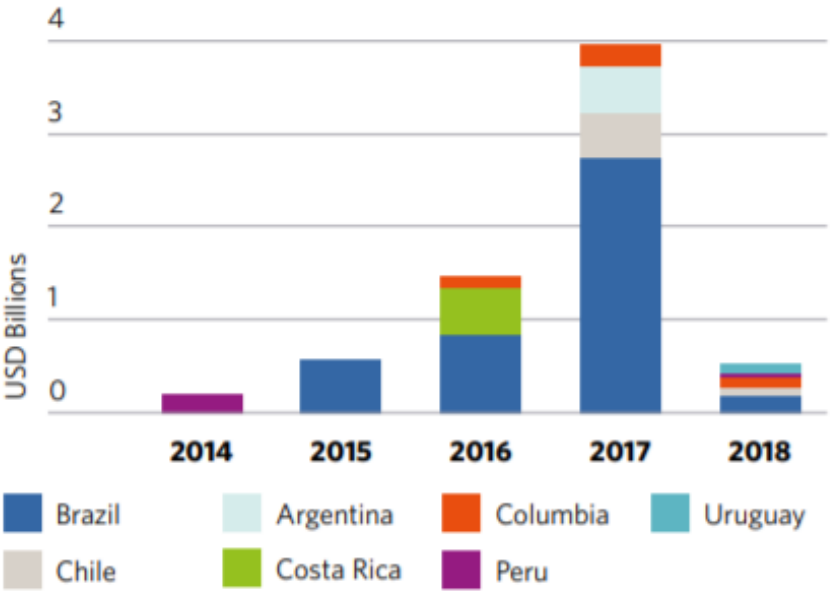

Fuente: $\mathrm{CBI}$, green bonds the state of the market 2018.

Sin embargo, respecto a la sensibilidad de los mercados existen criterios diversos de si son o no una restricción para el desarrollo de los BV. El resultado de estudio empírico de Flaherty et al ( 2017b), demuestra que aun en periodos de inestabilidad o alta volatilidad del mercado los inversores se sienten más atraídos por BV de largo plazo emitidos por organizaciones supranacionales y agencias gubernamentales, quienes garantizan el bajo riesgo de incumplimiento. Respecto a la estructura de la emisión el estudio de la CEPAL sobre el mercado de bonos alineados con el clima de ALC, muestra a partir de agosto de 2017 el total de emisiones (incluidas las emisiones de bonos nacionales e internacionales) está compuesto por 26 bonos de 22 emisores, con un valor total de bonos de ALC emitidos desde diciembre de 2014 a US \$ 8.4 mil millones, Del total de los recursos recibidos por la emisión en la región, el 32\% de los recursos fue direccionado al sector energía, el $24 \%$ a Trasporte y el $35 \%$ beneficiaban a múltiples sectores, el porcentaje restante a agua y agricultura (Ver fig.8).

Figura 8. Emisiones de bonos alineados con el clima de ALC por sector, 2014-2017

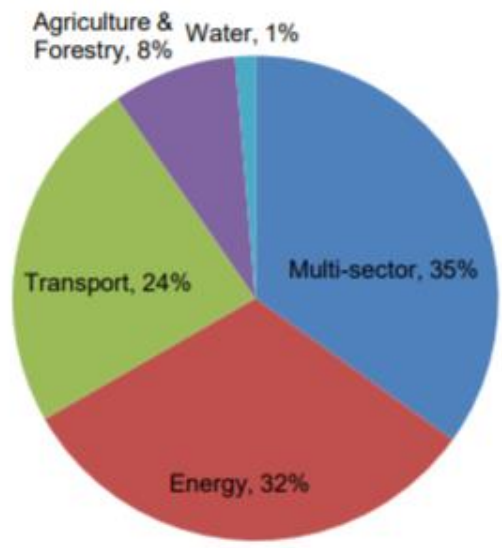

Fuente: ECLAC Washington Office, on the basis of data from LatinFinance and the Climate Bonds Initiative.

Según dicha fuente los emisores de bonos verdes más frecuentes en la región de América Latina y el Caribe han sido de Brasil y México (Figura 4). En conjunto, estos dos países representaron más del 70\% de todos los bonos con un enfoque verde emitidos en la región a agosto de 2017. 


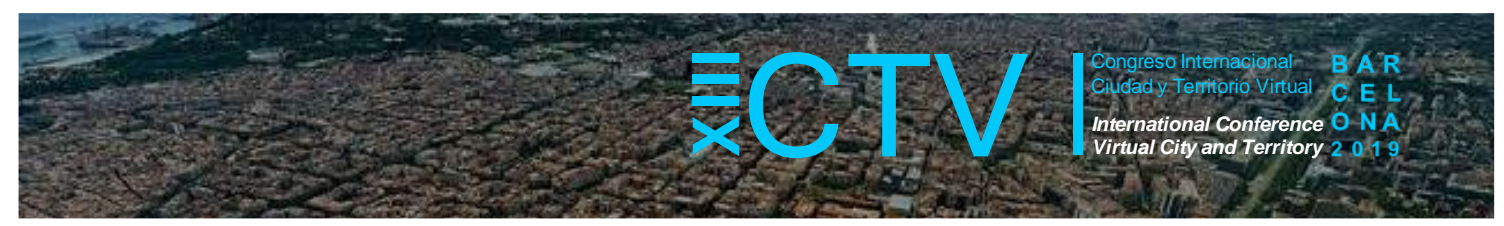

Para esta fuente, la mayoría de los bonos emitidos en este mercado provienen del sector público y entidades supranacionales. Cerca del $60 \%$ de los bonos en circulación son emitidos por gobiernos a diferentes niveles: locales y municipales, bancos de desarrollo regional y empresas estatales (Figura 10). Los emisores más importantes incluyen el Fideicomiso del Aeropuerto de la Ciudad de México (en 2016) y el BNDES de Brasil (en 2017).

Los fondos recaudados por Brasil a través de su banco de desarrollo BNDES han sido dirigido hacia proyectos de energía eólica y solar, Brasil dispone de emisores con una buena calificación crediticia local y global, provenientes del sector agrícola, forestal y energético. La productora de energía hidroeléctrica y eólica brasileña Omega Geração S.A., Itarema Geração de Energia S.A, CPFL Energias Renovaveis, y el Banco de Desarrollo BNDES, además corporaciones privadas como Suzano, Papel e Celulose22 BRFBrasil Food23 (CEPAL, 2017). Más del 50\% de los compradores de dichos bonos son europeos, principalmente de Alemania, Francia y Suiza (CBI, 2016 Edición portuguesa).

México ha impulsado través de la bolsa mexicana el mercado de bonos verdes, la mayor parte de las obligaciones han sido emitidas por el Aeropuerto internacional de México. según Credit Rating Agency, (2018), el desarrollo del mercado de bonos lo impulsa la iniciativa pública. El primer bono colocado en el mercado internacional fue realizado por la Banca de Desarrollo Nacional Financiera (NAFIN) en el 2015 y también emitió el primer bono en el mercado nacional en el 2016. Los recursos de esta entidad han sido dirigidos a la financiación de proyectos eólicos e hidráulicos. También ha emitido bonos el Gobierno de la Ciudad de México ${ }^{24}$ para financiar proyectos de transportes sustentables, manejo de agua, aguas residuales y de eficiencia energética. Adicionalmente Inversiones internacionales como los fondos verdes del Banco mundia ${ }^{25}$ están comprometidos para proyecto de eficiencia energética municipal de alumbrado público, uso de agua y edificios en 23 municipios mexicanos - Energía municipal (Banco Mundial,2018)

Los bonos dirigidos al aeropuerto internacional en el periodo expuesto ascienden a 2000 millones de dólares. Sin embargo, fuentes especializadas como El Economista (2019) ${ }^{26}$ afirman que luego del 2014 se emitieron otros bonos en dos tramos más hasta alcanzar 6000 millones a pagar en 10 y 30 años, dirigidos a inversionistas extranjeros, posteriormente luego de problemas de concreción de los proyectos y con una nueva administración gubernamental se renegoció la deuda y se pagó 1800 millones a inversionistas. En la actualidad aún quedan 4200 millones por

\footnotetext{
${ }^{22}$ Suzano Papel e Celulose es una empresa brasileña de pulpa y papel con presencia en más de 80 países. Es la compañía de pulpa y papel más grande de América Latina.

${ }^{23}$ BRF S.A. es una empresa brasileña. BRF es una de las compañías de alimentos más grandes del mundo, Sus productos se venden en más de 150 países, en los cinco continentes

${ }^{24}$ el Fideicomiso del Aeropuerto de la Ciudad de México (conectado con el banco de desarrollo de México NAFIN) emitió el bono verde más grande hasta la fecha en América Latina, recaudando US $\$ 2$ mil millones a través de un bono de dos ramas, que recibió la certificación de la Iniciativa de Bonos Climáticos. Los dos tramos se emitieron por separado con un valor nominal de US $\$ 1,000$ millones con vencimientos a 10 y 30 años y con tasas de cupón de $4.25 \%$ y $5.50 \%$, respectivamente (CEPAL, 2017) Los titulares de los bonos recibirán pagos a través de los flujos de efectivo generados por el tráfico aeroportuario existente en la Ciudad de México

25 Ampliar información http://documents.worldbank.org/curated/en/278581512756205073/pdf/SFG3845-EA-SPANISHP165585-Box405316B-PUBLIC-Disclosed-12-8-2017.pdf

26 Ampliar en : https://www.eleconomista.com.mx/empresas/Plazo-de-deuda-del-NAIM-bajo-de-30-a-19-anos20190812-0010.html
} 


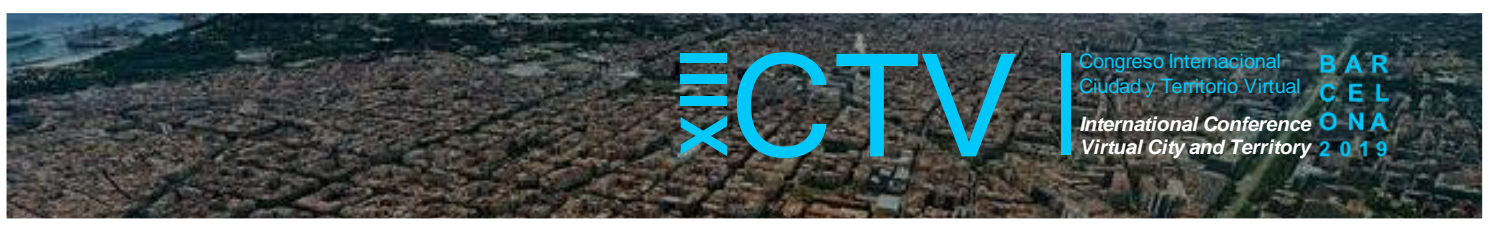

devolver a los bonistas. México, adicionalmente tiene un ejemplo interesante de emisión de bonos municipales (iniciado por EEUU) dirigido hacia el mercado local ${ }^{27}$.

Figura 10. La distribución de la emisión en la región en 2018. Periodo 2014-2017

\begin{tabular}{|c|c|c|c|c|}
\hline País & Nombre Emisor & $\begin{array}{l}\text { Emisión } \\
\text { US\$(millón) }\end{array}$ & Tipo de emisor & $\begin{array}{l}\text { Sector } \\
\text { beneficiado }\end{array}$ \\
\hline México & $\begin{array}{l}\text { Grupo Rotoplas } \\
\text { SAB, Banobras, } \\
\text { Mexico City, } \\
\text { México City } \\
\text { Airport Trust, } \\
\text { Nacional } \\
\text { Financiera } \\
\text { (NAFIN) }\end{array}$ & $2.997,00$ & $\begin{array}{l}\text { Banco de } \\
\text { Desarrollo, } \\
\text { corporación, } \\
\text { Municipal, Estado, } \\
\text { Vehículo Emisor }\end{array}$ & $\begin{array}{l}\text { Multi sector, } \\
\text { agua y } \\
\text { sanidad } \\
\text { Transporte, } \\
\text { Energía } \\
\text { eólica, }\end{array}$ \\
\hline Colombia & $\begin{array}{l}\text { Bancóldex, } \\
\text { Davivienda }\end{array}$ & 332,00 & Banco de Desarrollo & Multi sector \\
\hline Supranacional & $\begin{array}{l}\text { IIC (Invernegy } \\
\text { Wind), campo } \\
\text { Palomas Finance } \\
\text { Ltda, CABEI }\end{array}$ & 210,00 & $\begin{array}{l}\text { Banco, Vehículo } \\
\text { emisor }\end{array}$ & Energía \\
\hline Brasil & $\begin{array}{l}\text { Potami Energia } \\
\text { S.A, Intarema } \\
\text { Geraçáo de } \\
\text { Energía S.A, } \\
\text { BNDES, Fibria, } \\
\text { Suzano Papel e } \\
\text { Celulose, CPFL } \\
\text { Energias } \\
\text { Renovaveis, } \\
\text { Suzano Papel e } \\
\text { Celulose, BRF } \\
\text { Brazil Foods, }\end{array}$ & $3.154,00$ & $\begin{array}{l}\text { Corporación, Banco } \\
\text { de Desarrollo }\end{array}$ & $\begin{array}{l}\text { Energía } \\
\text { Eólica y } \\
\text { solar, } \\
\text { Agricultura, } \\
\text { Multi sector, } \\
\text { Corporación }\end{array}$ \\
\hline Chile & $\begin{array}{l}\text { Inversiones } \\
\text { CMPC }\end{array}$ & 500,00 & Corporación & Multi sector \\
\hline Argentina & $\begin{array}{l}\text { Province of la } \\
\text { Rioja, Gennela S. } \\
\text { A }\end{array}$ & 550,00 & $\begin{array}{l}\text { Municipal, } \\
\text { corporación }\end{array}$ & Multi sector \\
\hline Costa Rica & $\begin{array}{l}\text { Banco Nacional } \\
\text { de Costa Rica } \\
\text { (BNCR) }\end{array}$ & 500,00 & $\begin{array}{l}\text { Banco de } \\
\text { Desarrollo, Multi } \\
\text { sector }\end{array}$ & $\begin{array}{l}\text { Banco de } \\
\text { Desarrollo }\end{array}$ \\
\hline Perú & Energía Eólica & 204,00 & Corporación & Energía \\
\hline Total & & $8.447,00$ & & \\
\hline
\end{tabular}

Fuente: CEPAL Washington Office on the basis of data from Latin Finance and the Climate Bonds Initiative.

Elaborado: Autores, Adaptan la información

\subsection{Avances para el desarrollo de la inversión en el mercado verde}

La implementación del mecanismo se ha efectuado de manera heterogénea en los diferentes países de ALC, a nivel global el mercado no presenta la madurez de los países desarrollados, sin embargo, muestran un nivel significativo de avance. A continuación, se destacan dos países

Brasil, ha realizado esfuerzos para crear un ambiente regulatorio propicio para la reducción de emisiones e incentivo en el mercado de capitales. Ha iniciado un proceso importante de incentivos fiscales selectivos, los cuales eximen a los inversores extranjeros y a las personas de

\footnotetext{
${ }^{27}$ La Ciudad de México realizó la primera emisión municipal de bonos verdes en América Latina, a finales del 2016, por un monto de US $\$ 50$ millones cuyos recursos son asignados a proyectos de tratamiento de aguas residuales, eficiencia energética y mejoramiento del transporte público. Ampliar información https://www.expoknews.com/bonos-verdessociales-y-sostenibles-2a-parte-anaden-valor/
} 


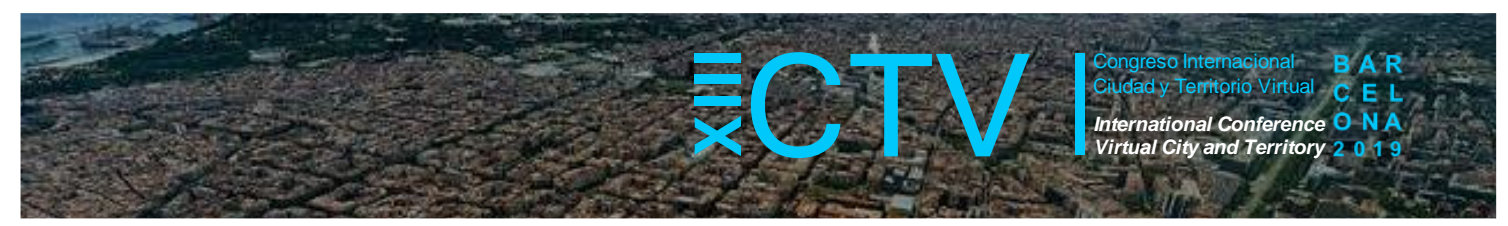

Brasil del pago del impuesto sobre la renta, no obstante reconocen que aún tienen que trabajar en la regulación del mercado de capitales, a fin de aumentar la liquidez, asi como aumentar la regulación de los fondos de pensiones (CBI Edición portuguesa, 2016). El avance político internacional ha sido importante para el desarrollo del mercado. Ambos países gozan de una posición diplomática internacional significativa en relación a los demás países de la región respecto negociación en aspectos de cambio climático, sobre todo Brasil que es un jugador importante en las negociaciones mundiales reflejada en Kioto (donde se incentiva el mercado de capitales).

Un factor positivo para el desarrollo del mercado de capital en México, ha sido el crecimiento económico sostenido que presenta desde 1994, incorporando también acuerdos comerciales importantes, periodos de estabilidad macroeconómica ${ }^{28}$; en combinación con una baja inflación ${ }^{29}$ y un sólido mercado doméstico (CBI, 2016). Los actores públicos municipales han iniciado el apoyo para el desarrollo del mercado a través de los bonos municipales ${ }^{30}$, los municipios con una buena calificación crediticia pueden tener acceso a los recursos. México tiene ya una iniciativa de emisión por 49 millones de dólares (CEPAL,2017).

A nivel general en lo relacionado a la inversión municipal, el mayor interés de financiación para las ciudades es especialmente en el alumbrado público (CBI, 2016 Edición portuguesa). De acuerdo con ONU-Hábitat ${ }^{31}$, y esto es importante porque las ciudades consumen el $78 \%$ de la energía mundial y producen más del $60 \%$ de las emisiones de gases de efecto invernadero. Aunque abarcan menos del $2 \%$ de la superficie de la tierra.

\subsection{Las principales barreras para el desarrollo del mercado en Latinoamérica}

Para Rodríguez et al (2015), entre las barreras importantes para el desarrollo global del mercado de capitales están: la heterogeneidad de la estructura económica social y política que no le permite el desarrollo de su mercado interno, su aparato productivo primario no especializado en servicios financieros, una estructura institucional financiera débil ante la influencia que ejerce el gran capital financiero internacional y en especial su constante inestabilidad o volatilidad, según esta fuente el desempeño de los mercados de valores de América Latina no ha sido el mejor en los últimos diez años, la cual sigue siendo muy mínima si se compara con otras regiones. De la Torre y Schmukler (2005) agrega que la inseguridad jurídica es uno de los motivos para que las bolsas de valores internas no se desarrollen y contribuyan al proceso, es la emigración de las grandes empresas a las bolsas internacionales.

Para el MDL y en el marco de la heterogeneidad que presentan los diversos paises, investigadores identifican como barreras los regímenes legales débiles, la falta de capacidad institucional y experiencia para hacer que este mercado funcione, los altos costos en el proceso de registro de MDL, tales como todo el trabajo requerido para iniciar, emprender y administrar

\footnotetext{
28 Reporte de Competitividad Global 2015 - 2016: http://www3.weforum.org/docs/gcr/20152016/Global_Competitiveness_Report_2015-2016.pdf

${ }^{29}$ Inflation.eu http://www.inflation.eu/inflation-rates/mexico/historic-inflation/cpi-inflation-mexico.aspx

${ }^{30}$ Las ciudades se encuentran entre los mayores consumidores de energía del mundo, y representan más del $70 \%$ de las emisiones de gases de efecto invernadero. Los bonos verdes pueden generar ganancias de eficiencia energética para la industria del alumbrado público mediante la implementación de nuevas tecnologías como el LED. Según un estudio realizado por el Banco Mundial para Brasil, los LED llevaran al país a ahorrar un $2 \%$ de su consumo actual de electricidad.

Ver.http://www.esmap.org/sites/esmap.org/files/DocumentLibrary/TRACE Rio De Janeiro Deployment.pdf

${ }^{31}$ Ampliar información: https://www.un.org/es/climatechange/cities-pollution.shtml
} 


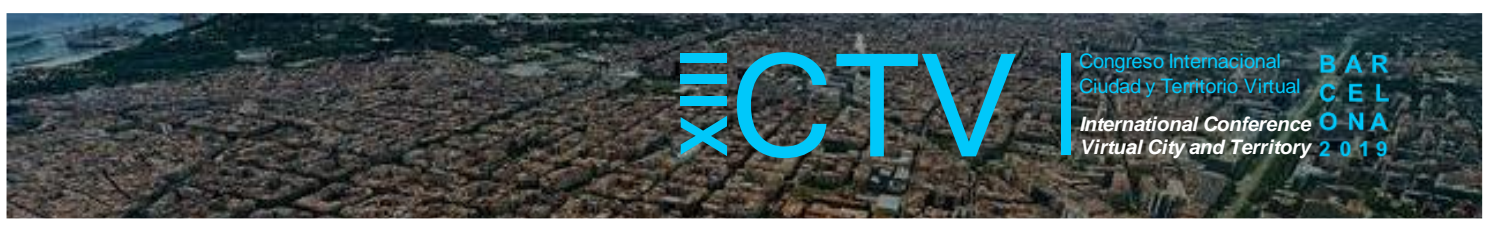

un proyecto de MDL, que involucra muchas tareas burocráticas complejas que el ciclo de MDL (Benites, 2013).

Según Girardin (2013) entre las barreras propias de la normatividad del MDL, está el requisito de adicionalidad. Latinoamérica ha implementado obras de menor costo en la reducción de emisiones, principalmente entre las décadas del 70 y del 90, lo que constituye una línea base importante y no le da espacio a la adicionalidad, lo cual lo pone en desventaja relativa respecto a países que postergaron la aplicación de dichas medidas y por lo tanto demuestran una mayor adicionalidad.

A nivel general el mercado de capital latinoamericano, continuamente se ve sometido a inestabilidades políticas y económicas. Según el Banco Mundial esto obstaculiza el principio del inversor de bajo riesgo y rápido retorno del capital. Además presenta insuficiencia de seguridad en el flujo de caja, estabilidad en el cumplimiento de las leyes y contratos, eficiencia en la administración del estado y ausencia de interferencias del gobierno en la gestión de las inversiones (Eguren et al., 2007).

Respecto a los bonos verdes Banga (2019), afirma que el mercado está polarizado en economías desarrolladas y emergentes, estas últimas presentan mayores desafíos que pueden ser atenuados si se toman las medidas pertinentes. El autor, sustentando su afirmación en otros investigadores, afirma que los problemas son:

- Institucionales, debido al inadecuado manejo de procedimientos de emisión a fin de que alcancen la conformidad con los GBP, existen falta de estándares comúnmente acordados para los bonos verdes. Existe conflicto de intereses al interior de los organismos oficiales de los sectores ambientales y financieros

- Barreras del mercado, tales como: el tamaño mínimo de la emisión, la moneda de emisión y los altos costos de transacción asociados con la emisión de bonos verdes. Según el autor para los inversores privados es importante el el tamaño, la tenencia y la liquidez de los bonos verdes. Algunas agencias de calificación de riesgo crediticio del mundo como Moody's, afirman que los bonos verdes deben de tener un valor mínimo de USD 250 millones para ser elegibles para la inclusión en un índice bursatil. Sin embargo, los proyectos verdes implementados en países en desarrollo son de pequeño tamaño. Luego, los costos de transacción o costos incurridos por el emisor para obtener una certificación de etiqueta verde son muy altos, especialmente cuando se requiere una certificación de solvencia del emisor, por parte de un tercero (el costo podría oscilar entre USD 10 y 100 mil dólares)

- Una barrera no despreciable para la propagación de los bonos verdes en los países en desarrollo es probablemente la moneda de emisión. Los inversores generalmente usan Renminbi (32\%), el dólar estadounidense (26\%) y el Euro (20\%). La mayoría de los paises de ALC tienen monedas no convertibles, por lo que deben emitir sus bonos verdes en monedas internacionales, para incurrir en los mercados financieros internacionales, lo que conlleva un riesgo cambiario, ya que los flujos de ingresos del proyecto a financiar generalmente se relacionan con las monedas locales.

Segun informe de $\mathrm{CBI}$,edicion portuguesa (2016), otro problema es que los mercados latinoamericanos son pequeños y pocos diversificados sigue dominado por emisiones soberanas 


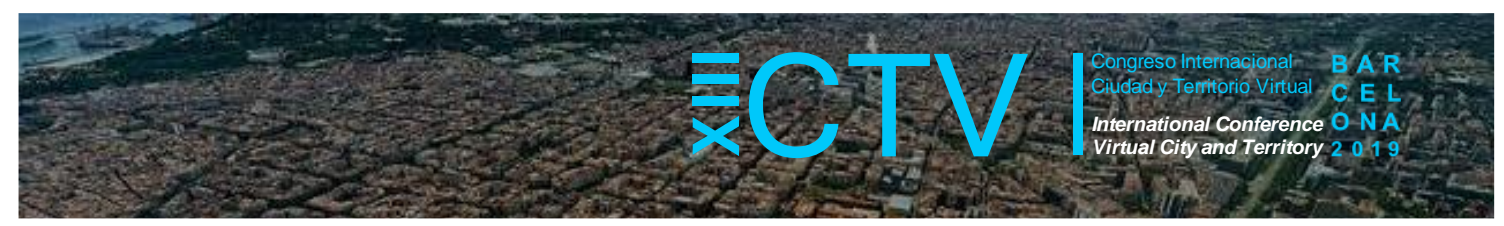

(bonos de gobierno), lo cual trae problemas de liquidez ${ }^{32}$. El entorno político y económico, como se notó en el 2018 en el caso de la emisión de Brasil, puede disuadir a los inversores internacionales de comprar bonos. Una mejor estabilidad económica facilitaría el cambio de horizontes del corto plazo en términos de planificación de inversiones

Autores como Franklin (2016), afirman que una de las medidas para incentivar al inversor puede ser: la Implementación del despojo verde ${ }^{33}$, el cual consiste en que un emisor puede emitir un bono destinado a financiar proyectos verdes y no verdes en lugar de emitir un bono verde al cien por cien, en países con alta solvencia crediticia . Para Pinheiro Neto et al (2017), el Gobierno para alentar el mercado puede cubrir todos los costos de transacción asociados con la emisión de bonos verdes, de modo que el costo de emitir un bono verde esté a la par con el de emitir un bono convencional. Dicho autor, además, afirma que sería necesario aplicar optimización a la inversión de carteras para proyectos de energía renovable, a través de un estudio empírico para Brasil, demuestra que la deuda tiene una influencia directa en el proceso de diversificación y los resultados económicos.

\section{Conclusiones}

El mercado de capitales, aunque presenta un avance relativo, tiene aún grandes desafíos, de maduración, para lo cual requiere aplicar una reforma que implique en sus inicios fortalecer la banca pública y, en particular, la banca de desarrollo, como un instrumento que permita al sistema potenciar y democratizar el acceso al crédito, hasta que las corporaciones privadas se integren al mismo. Se comparte el criterio del horizonte de largo plazo para las inversiones en el sistema financiero propuesta por la CEPAL (2010) y en donde la banca privada sea sometida a una mayor regulación y supervisión de manera que se sustraiga cualquier intento de especulación. Además de contrarrestar la volatilidad externa (flujos de corto plazo), a través de una política macroeconómica aplicable a la cuenta de capital.

EI MDL como instrumento financiero ha sido importante en el desarrollo de la política energética de la región oficializado mediante el Protocolo de Kioto ${ }^{34}$, ha jugado un papel destacable en las inversiones, sobre todo en los primeros años de implementación. Las RCEs proveniente de Latinoamérica han incursionado el Mercado Internacional de Carbono. Sin embargo, su implementación ha sido desalentada por los bajos precios, producto de la caída de la demanda, esto evidencia que los GEI está sometida a los intereses del mercado y de la poca voluntad de los países desarrollados para reducirlas.

Como se evidenció en este estudio, el RCE conforma el rubro de los créditos internacionales que utilizan los países desarrollados para cumplir sus compromisos de reducción de emisiones; no obstante, el problema es que oficialmente la demanda ha decaído y el instrumento tiene

\footnotetext{
32 En el mundo de las inversiones, cuando un activo es poco líquido significa que no se negocia de manera frecuente. Cuando se necesita vender de forma urgente ese activo poco líquido (ya sea una vivienda, un bono u otro activo). Al no existir un mercado líquido, habrá muy pocos compradores dispuestos a adquirir ese activo. Por lo que probablemente tengamos que bajar el precio del activo para poder atraer a los compradores interesados y venderles dicho activo.

${ }^{33}$ Un emisor podría emitir un bono destinado a financiar proyectos verdes y no verdes en lugar de emitir un bono verde al cien por cien. En ese caso, solo una fracción de los ingresos de ese bono, la franja verde, debe usarse para financiar el proyecto verde

${ }^{34}$ La primera iniciativa global de orden práctico para promover el desarrollo sostenible
} 


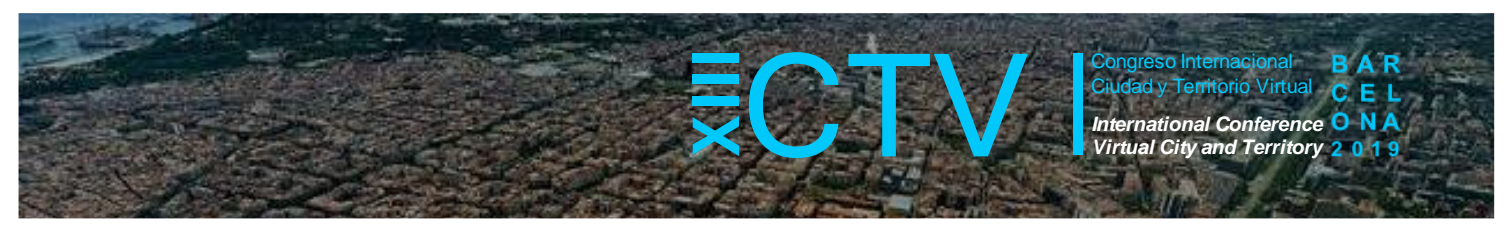

vigencia solo hasta el $2020^{35}$. Cabe destacar que, entre las fortalezas de este mecanismo, se encuentra el impulso de institucionalización del mecanismo desde espacios internacionales (Protocolo de Kioto), en un contexto de cooperación entre países desarrollados y en vías de desarrollo. Además de la disposición de metodologías oficiales que permitían a nivel técnico cuantificar el impacto del mecanismo sobre las emisiones del GEl.

La vigencia del MDL después del 2020 es incierto, el Consejo Consultivo del MDL ha pedido a la secretaría de la Convención Marco de la ONU sobre el Cambio Climático (CMNUCC) que lleve a cabo un análisis de las opciones posibles para utilizar el MDL como una herramienta para otros usos, sin embargo, no hay nada claro. Si prolonga su vigencia debería revisarse con más detalles los mecanismos de adicionalidad y sobre todo revisar los factores que afectan la demanda y provocan bajos precios a fin de tomar medidas correspondientes.

Los bonos verdes se perfilan como sucesores de los MDL, sin embargo, aún tiene un largo camino para su desarrollo, se caracteriza por que son instrumentos financieros exclusivos de mercado, sujetos al libre el juego de la oferta y la demanda. No estan visualizados como instrumentos oficiales de reducción de emisiones desde negociaciones climaticas mundiales como ocurria con los MDL.Su desarrollo ha sido pequeño en ALC, sujeto a inestabilidades permanentes. La fortaleza de la emisión sería la oficialidad del instrumento y crear mecanismos financieros con ventajas y apoyo a los paises con estructuras financieras mas debiles, para atenuar las reglas egoistas de mercado.

Los actores en la implementación de los dos mecanismos son de iniciativa pública, lo cual es importante para el despegue de los mecanismos, no obstante, para la salud de las finanzas estatales es necesario que se adhiera al proceso las corporaciones privada. Enel análisis comparativo Brasil empresas como Suzano Papel e Celulose y BRF Brazil Foods y alguna en México han iniciado un proceso de emisión, y en menor proporción otras corporaciones de Argentina y Perú también. Un factor también importante para revisar es el tamaño del mercado, es muy pequeño y presenta problemas de liquidez, los inversores no tienen amplitud para vender el activo, en caso de imprevistos, debido a lo reducido del mercado, corren el riesgo de vender sus activos a precios reducidos para atraer a otros inversores.

La falta de diversificación de la inversión también es un problema a resolver Brasil y muchos países de América Latina han concentrado su inversión en fuentes hidráulica; sin embargo, hay un peligro latente por los cambios meteorológicos propios del cambio climático como la ausencia de lluvias, por lo cual es necesario la diversificación de la inversión incorporando tecnologías eólicas y la fotovoltaicas.

A nivel general la promoción del cuidado del ambiente y de las finanzas verdes debe surgir desde las administraciones gubernamentales, es claro que su expansión del mercado financiero requiere la superación de desafíos estructurales y de desarrollo del mercado de capital y sobre todo en un contexto de largo plazo. Además, requiere políticas de crecimiento y desarrollo que presente una ALC que presente reducidos riesgos políticos, macroeconómicos, baja inflación y bajos riesgos crediticios.

\footnotetext{
${ }^{35}$ De acuerdo al informe Bruselas, 17.12.2018 COM (2018) 842 final, los participantes en el RCDE UE pueden utilizar créditos internacionales procedentes del Mecanismo de Desarrollo Limpio (MDL) y de la aplicación conjunta (AC) del Protocolo de Kioto para cumplir parte de sus obligaciones en el marco del RCDE UE solo hasta 2020
} 


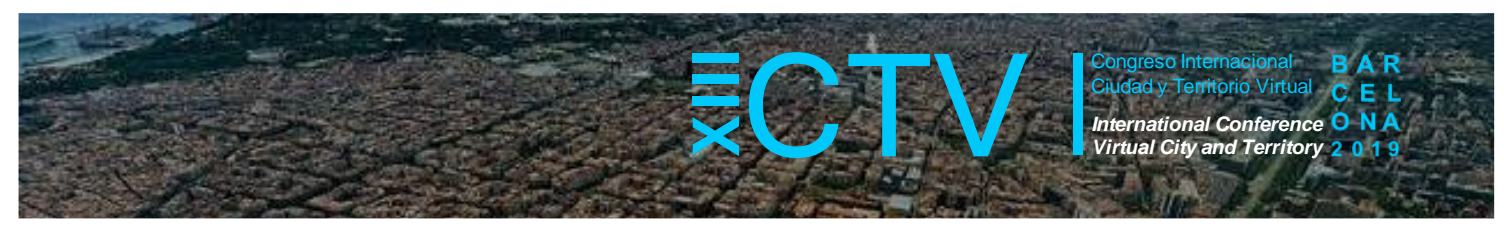

A nivel técnico en el desarrollo del mecanismo, es necesario desarrollar metodologías de cuantificación de reducción de emisiones más firmes para los BV aún en su contexto de libre mercado. Los bonos verdes enuncian estar alineados a los principios de emisión (GBP) e informan sobre el destino de los recursos, no obstante, es necesario una cuantificación más estricta sobre la cantidad de emisiones reducidas era uno de los factores positivos de los MDL

Concluyendo se puede decir que si bien ha existido una afluencia de recursos hacia Latinoamérica especialmente con el primer instrumento; los resultados encontrados en esta investigación, deben ser el inicio de una investigación empírica que mida el verdadero impacto de la inversión alineada al clima, desde la óptica del aumento de la capacidad instalada y la reducción de emisiones de GEI. De tal manera que esta experiencia agregue nuevas estrategias para inversiones futuras.

Agradecimientos: Los Autores agradecen de manera especial y sincera a Jordi Ferrón i Llaguerri de FREMAP por su acompañamiento en el desarrollo de esta investigación.

Conflicto de Intereses: Los autores declaran que no hay conflicto de intereses.

\section{Bibliografía}

Abadía (2013). La experiencia del comercio de derechos de emisión como herramienta para mitigar las emisiones de gases de efecto invernadero Recuperado de http://www.funseam.com/phocadownload/Informes/informe funseam revisin gas efecto inver nadero-jesus abada ibaez.pdf

ALIDE (2019) Documento técnico Mercado de bonos verdes. Quiénes son sus protagonistas. (s. f.). Recuperado de http://www.alide.org.pe/wp-content/uploads/2019/03/Documentot\%C3\%A9cnico-Mercado-de-bonos-verdes-Qui\%C3\%A9nes-son-sus-protagonistas-Final.pdf

Banco Mundial (2018) Report impact green-bond 2018. Recuperado de http://pubdocs.worldbank.org/en/632251542641579226/report-impact-green-bond-2018.pdf

Banga, J. (2019). The green bond market: a potential source of climate finance for developing countries. Journal of Sustainable Finance \& Investment, 9(1), 17-32. DOI https://doi.org/10.1080/20430795.2018.1498617

Benites-Lázaro, L. (2015). A participação da América Latina no Mecanismo de Desenvolvimento Limpo. Sustentabilidades. v. 5, n. 11.

Benites-Lazaro, L.; Gremaud, P. A., \& Benites, L. A. (2018). Business responsibility regarding climate change in Latin America: An empirical analysis from Clean Development Mechanism (CDM) project developers. The Extractive Industries and Society, 5(2), 297-306. DOI https://doi.org/10.1016/j.exis.2018.02.011

Benites-Lázaro, L. (2013). O Mecanismo de Desenvolvimiento Limpo na América Latina: Contribuição para o Desenvolvimento Sustentável e à Responsabilidade Social Empresarial. Tese (Doutorado). Universidade de São Paulo- USP, São Paulo. 


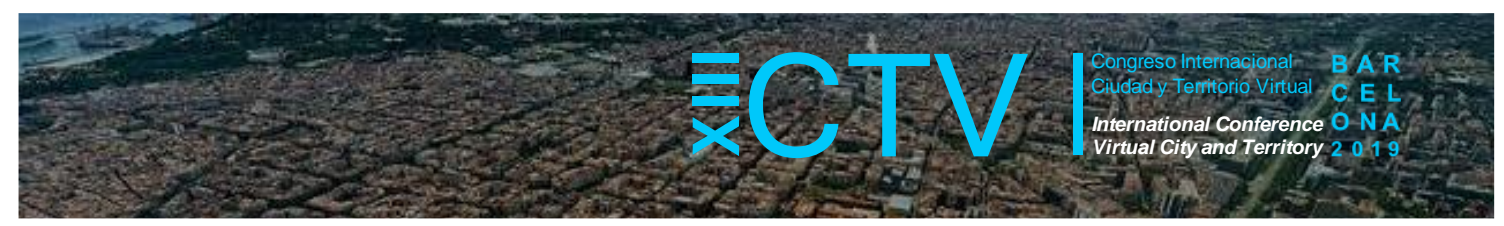

Benites, L. (2015) América Latina en la negociación del acuerdo sobre.pdf. Recuperado de https://clacsoambientalglobal.files.wordpress.com/2015/12/indcs-amc3a9rica-latina.pdf

CEPAL (2010). "La hora de la igualdad: brechas por cerrar, caminos por abrir". Trigésimo tercer período de sesiones de la CEPAL, Brasilia, 30 de mayo a 1 de junio del 2010, 291p.

Climate Bond Initiative. (2018). Bonos y Cambio Climático - Estado del Mercado. Recuperado de https://www.climatebonds.net/resources/reports/bonds-and-climate-change-state-market-2018/ spanish

CEPAL. (2017). The rise of green bonds: Financing for development in Latin America and the Caribbean. Recuperado de https://www.cepal.org/en/publications/42230-rise-green-bondsfinancing-development-latin-america-and-caribbean

Climate Bonds Initiative. (2016). Bonos y Cambio Climático-Estado del Mercado. Recuperado de https://www.climatebonds.net/files/files/Spanish\%20SotM\%20Interactive.pdf

Climate Bonds Initiative. (2016). State of the Market 2016 Brazil Edition Portuguese. Recuperado https://www.climatebonds.net/files/files/State\%20of\%20the\%20Market\%202016\%20Brazil\%20E dition\%20Portuguese\%20A4\%281\%29.pdf

Climate Bonds Initiative. (2016). Bonos y Cambio Climático 2016. Estado del mercado-México. https://www.climatebonds.net/files/files/SotM\%202016\%20Mexico\%20Spanish\%20Edition.pdf

Credit Rating Agency (2018). Crecimiento de Bonos Verdes, Sociales y Sustentables en México. Recuperado de https://www.hrratings.com/pdf/Sectorial\%20Bonos\%20Sustentables.pdf

Chiang, J. (2017). Growing the US Green Bond Market -Volume 1: The Barriers and Challenges. California Treasury. http://www.treasurer.ca.gov/greenbonds/publications/reports/green_bond_ market_01.pdf

De la Torre, A. y Schmukler, S. (2005). ¿Hacia dónde van los mercados de capital de América Latina? http://wwwwds.worldbank.org/external/default/WDSContentServer/WDSP/IB/2005/08/03 /000160016_20050803174326/Rendered/PDF/331980SPANISH0Apr051661Cap1Mkts1SP.pdf

Eguren C., L. (2007). Mercado de energías renovables y mercado del carbono en América Latina: estado de situación y perspectivas. N.U. CEPAL, División de Recursos Naturales e Infraestructura. https://repositorio.cepal.org/bitstream/handle/11362/6317/1/S2007605_es.pdf

Franklin. (2016). Just add stripes. Diversity in the environmental asset class is suffering from high minimum issuance sizes and monitoringcosts. Green striping could be the solution https://heinonline.org/HOL/LandingPage?handle=hein.journals/intfinr35\&div=170\&id=\&page=

Flaherty, M., Gevorkyan, A., Radpour, S., \& Semmler, W. (2017a). Financing climate policies through climate bonds - A three stage model and empirics. Research in International Business and Finance, 42, 468-479. DOI https://doi.org/10.1016/j.ribaf.2016.06.001

Girardin. (2013). Foro sobre cambio climático Ver. http://www.ambienteycomercio.org/el-mdl-enamerica-latina/. 


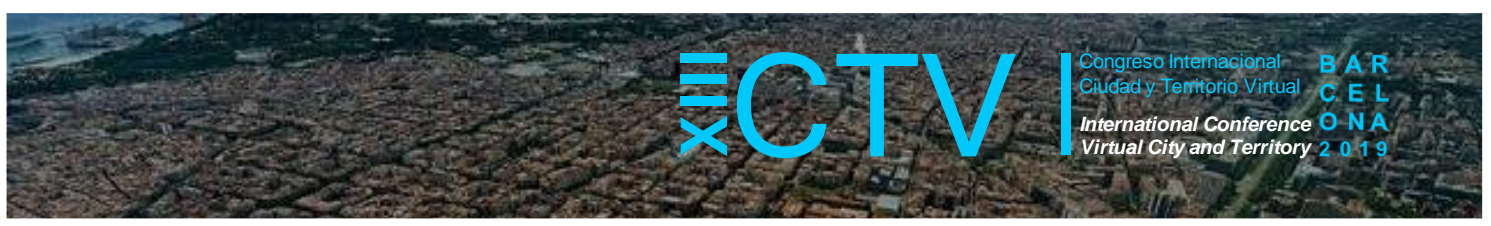

Gobierno de España- Ministerio de Transición Ecológica. (2019). La Convención Marco de Naciones Unidas sobre el Cambio Climático (CMNUCC). Recuperado de https://www.miteco.gob.es/es/cambio-climatico/temas/el-proceso-internacional-de-lucha-contrael-cambio-climatico/naciones-unidas/CMNUCC.aspx

IPCC. (2013). EI Quinto informe de evaluación. Que implica para Latinoamerica. Recuperado de https://cdkn.org/wp-content/uploads/2014/12/INFORME-del-IPCC-Que-implica-paraLatinoamerica-CDKN.pdf.

IRENA. (2016). Análisis del Mercado de Energías Renovables: América Latina.

Jimenez, R. (2007). Mecanismos de Desarrollo Limpio para el Financiamiento Ambiental en América Latina. Recuperado en https://www.researchgate.net/publication/267681716_ Mecanismos_de_Desarrollo_Limpio_para_el_Financiamiento_Ambiental_en_America_Latina

Ledezma Rodríguez, M., \& Caballero Quintero, Y. (2013). Analysis framework for clean development's mechanism and the opportunities of the carbon market for Colombian development. Producción + Limpia, 8(1), 48-79.

México 2 (2018) Guia de Bonos Verdes para el Perú. Recuperado de https://www.a2g.pe/guia_peru_mexico2.pdf

OLADE. (2018). Panorama energético de América Latina y El Caribe. Recuperado de http://biblioteca.olade.org/opac-tmpl/Documentos/old0416b.pdf

Pinheiro Neto, D., Domingues, E. G., Coimbra, A. P., de Almeida, A. T., Alves, A. J., \& Calixto, W. P. (2017). Portfolio optimization of renewable energy assets: Hydro, wind, and photovoltaic energy in the regulated market in Brazil. Energy Economics, 64, 238-250. https://doi.org/10.1016/j.eneco.2017.03.020

PNUMA-U. EUROPEA, (2015) El acuerdo de Paris y sus implicaciones para América Latina y el Caribe. Ver: https://es.scribd.com/document/354720254/Acuerdo-de-Paris-Implicaciones-enALC-Estudio-1

Reguero, B. G., Losada, I. J., Díaz-Simal, P., Méndez, F. J., \& Beck, M. W. (2015). Effects of Climate Change on Exposure to Coastal Flooding in Latin America and the Caribbean. PLOS ONE, 10(7), e0133409. https://doi.org/10.1371/journal.pone.0133409

Rodríguez et al (2015). El mercado de capitales en América Latina 1990-2013. Ver. http://www.usc.es/econo/RGE/Vol24/rge2433.pdf

UNFCCC (2011) Informe anual de la Junta Ejecutiva del mecanismo para un desarrollo limpio a la Conferencia de las Partes en calidad de reunión de las Partes en el Protocolo deKyoto.Ver: https://unfccc.int/documents?f\%5B0\%5D=document type\%3A531\&search2=\&search3=\&page= $\underline{0 \% 2 \mathrm{C} 0 \% 2 \mathrm{C} 47}$.

UNFCCC (2012) Informe Anual de la Junta Ejecutiva de Mecanismo de Desarrollo Limpio. 


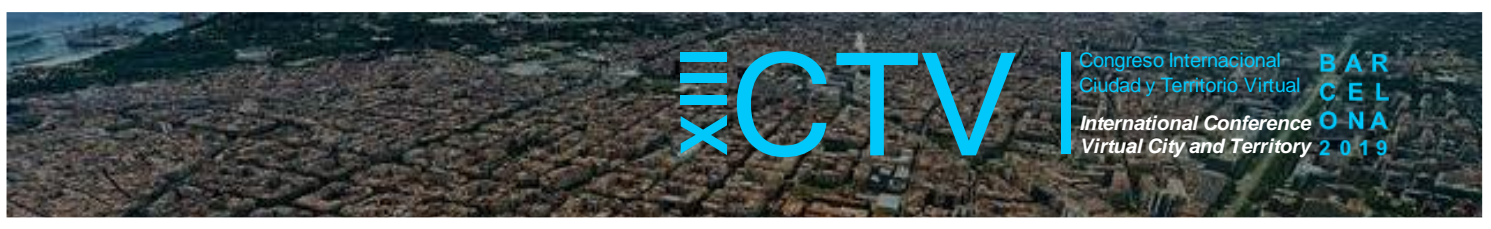

UNFCCC (2019) Proyectos MDL por región. Recuperado de https://cdm.unfccc.int/Statistics/Public/files/201908/proj_reg_byRegion.pdf

UNFCCC (2019) Protocolo de Kioto. Recuperado 11 de septiembre de 2019, de https://unfccc.int/resource/docs/convkp/kpspan.pdf

SENER -México (2012). Prospectiva de Energías Renovables 2012 - 2026. 156. Ver https://www.gob.mx/cms/uploads/attachment/file/62954/Prospectiva de Energ as Renovables 2012-2026.pdf

Sheinbaum-Pardo, C., \& Ruiz, B. J. (2012a). Energy context in Latin America. Energy, 40(1), 3946. https://doi.org/10.1016/j.energy.2011.10.041

Silveira, I. H., Oliveira, B. F. A., Cortes, T. R., \& Junger, W. L. (2019). The effect of ambient temperature on cardiovascular mortality in 27 Brazilian cities. Science of The Total Environment, 691, 996-1004. https://doi.org/10.1016/j.scitotenv.2019.06.493

UNEP DTU (2019) Database. Recuperado 17 de septiembre de 2019, de http://www.cdmpipeline.org/cdm-projects-region.htm. Revisada el 14 de septiembre 2019

Villavicencio Calzadilla. (2013). La Contribución al desarrollo sostenible del Mecanismo para un Desarrollo Limpio. Universitat Rovira y Virgili. Recuperado 2o septiembre de 2019, de https://www.tesisenred.net/handle/10803/129169?show=full

World Bank (2015) Que son los Bonos Verdes? (s. f.). Recuperado de http://documentos.bancomundial.org/curated/es/165281468188373879/pdf/99662-

REPLACEMENT-FILE-Spanish-Green-Bonds-Box393223B-PUBLIC.pdf 